No. 20-4

\title{
Wealth Distribution and Retirement Preparation Among Early Savers
}

\author{
Lindsay Jacobs, Elizabeth Llanes, Kevin Moore, \\ Jeffrey Thompson, and Alice Henriques Volz
}

\begin{abstract}
:
This paper develops a new combined-wealth measure by augmenting data on net worth from the Survey of Consumer Finances with estimates of defined benefit (DB) pension and expected Social Security wealth. We use this concept to explore retirement preparation among two groups of households in pre-retirement years (aged 40 through 49 and 50 through 59), and to explore the concentration of wealth. We find evidence of moderate, but rising, shortfalls in retirement preparation. We also show that including DB pension and Social Security wealth results in markedly lower measures of wealth concentration, and it slightly moderates trends toward a higher concentration over time.
\end{abstract}

\section{JEL Classifications: D31, D63, H55, I32}

Keywords: retirement adequacy, wealth inequality, Social Security

Linday Jacobs is an assistant professor at the University of Wisconsin's La Follette School of Public Affairs; her email is lpjacobs@lafollette.wisc.edu. Elizabeth Llanes is a PhD student in the University of Wisconsin's Department of Economics; her email is llanes@wisc.edu. Kevin Moore is the chief of the Microeconomics Survey Section in the Research and Statistics department of the Board of Governors of the Federal Reserve System; his email is kevin.b.moore@frb.gov. Jeffrey Thompson is a vice president and economist in the research department of the Federal Reserve Bank of Boston; his email is jeffrey.thompson@bos.frb. Alice Henriques Volz is a principal economist in the Microeconomics Survey Section in the Research and Statistics department of the Board of Governors; her email is alice.h.volz@frb.gov.

The authors thank John Sabelhaus; seminar attendees at NTA, George Mason University, the Congressional Budget Office, and the Federal Committee on Statistical Methodology for useful comments and feedback; and Melissa Gentry for excellent research assistance.

This paper presents preliminary analysis and results intended to stimulate discussion and critical comment. The analysis and conclusions set forth are those of the authors and do not indicate concurrence by other members of the research staff of the Board of Governors, the Federal Reserve Bank of Boston, or the University of Wisconsin.

This paper, which may be revised, is available on the website of the Federal Reserve Bank of Boston at https://www.bostonfed.org/publications/research-department-working-paper.aspx.

This version: February 2020

https://doi.org/10.29412/res.wp.2020.04 
The wealth that households accumulate during their working years - through pensions, housing equity, and other types of assets - is crucial in providing support to sustain them in retirement. There is a large literature evaluating the adequacy of retirement resources among retirees and households transitioning into retirement, and there is also a growing literature using wealth data to explore inequality in the distribution of economic resources - beyond the more traditional emphasis on income and consumption. This paper uses the Federal Reserve Board's triennial Survey of Consumer Finances (SCF) to contribute to each of these areas of research.

The SCF is the only household survey that provides adequate coverage of high-net-worth households in the United States. The wealth concept in the survey, market wealth, is incomplete, however, particularly when evaluating retirement resources. Importantly, household wealth in the SCF does not adequately reflect the asset value of defined benefit (DB) pensions. Further, it does not include the value of the future Social Security benefits that workers will accrue over their lifetime. These additional forms of wealth are important resources to retirees, but they also impact decisions leading up to retirement. Crucially, they disproportionately benefit households below the top portion of the wealth distribution. Therefore, they are vital for understanding the full distribution of wealth and for assessing the adequacy of savings of workers who will be transitioning into retirement in the future.

We develop an expanded definition of household wealth ("combined" wealth). First, we augment the asset and debt information collected in the SCF with estimates of the asset value of both traditional DB pensions and expected Social Security benefits. Second, we project SCF net worth following income-wealth-specific growth patterns observed in the survey, creating a wealth measure with timing that is in line with the estimation of expected Social Security wealth at the 
early eligibility age. We also project forward our DB estimates to reflect expected accumulation of benefits from one's current job.

We first use this combined-wealth concept to evaluate the resources of households approaching retirement age. Most of the retirement-adequacy literature focuses on recently retired or aboutto-retire workers. We evaluate preparation among households whose heads are in their 50s, similarly to existing studies, but also among a cohort of "early savers," households whose heads are in their 40s. Consistent with much of the literature, we find that expected retirement income is adequate for most households, but leaves a substantial—and growing — number at risk financially during their retirement years. ${ }^{1}$

We next use the expanded-resource concept to calculate levels and changes in the distribution of wealth over time. Some of the existing research exploring the distribution of wealth uses data that do not include households at the very top of the wealth distribution, and most of the data do not reflect either the implied asset value of DB pensions or Social Security. ${ }^{2}$ Incorporating the asset value of expected retirement benefits, particularly Social Security, has a dramatic equalizing effect on the distribution of wealth. For example, among households with heads aged 40 to 49 , the top 5 percent's share of wealth excluding retirement plans (defined-benefit [DB], defined-contribution [DC]) and Social Security is 53 percent. Once these assets are included, the top 5 percent's wealth share falls to 38 percent. There is also a slight moderation in the trend toward greater inequality once we incorporate all forms of retirement wealth.

\footnotetext{
1 Using administrative data, both Bee and Mitchell (2017) and Beshears et al. (2019) find that income in retirement, on average, has not fallen dramatically over the past 10 to 20 years. Beshears et al. (2019) do show deterioration for those with below-median income.

${ }^{2}$ Wolff $(2014,2015)$ is the primary exception here, as he also uses the SCF and predicts earnings histories. His focus is primarily on the Gini coefficient and broad inequality trends, not specifically top-end concentration. There are also a several methodological differences between this paper and Wolff's papers.
} 
In the remainder of this paper, we:

- briefly review the retirement-adequacy and wealth-inequality literatures, drawing attention to the contributions that we make in this paper

- describe the primary data we use in this analysis - the SCF

- detail the methods and additional data sources we use in estimating household-level earnings histories, which are used to calculate expected Social Security benefits and ageforward the private wealth measures to the point of retirement

- present our findings, both for retirement preparation and for the distribution of wealth

\section{Literature Review}

Retirement-income adequacy and wealth concentration have each generated an extensive literature. With a focus on identifying this paper's contributions, we provide a very brief overview of these two literatures.

\section{A. Retirement Adequacy}

The extensive literature evaluating the adequacy of income for current and future retirees has been spurred by dramatic changes in the demographics of an aging country and equally dramatic changes in our retirement system, which has transformed from a primarily defined-benefit (DB) pension system to an overwhelming defined-contribution (DC) system in just a few decades. The now-ubiquitous 401(k) plan was introduced into law in 1978. As of the late 1980s, traditional DB pensions were still the typical plan for households with heads aged 40 to 59. In 1989, 25 percent of these households were covered by a traditional defined benefit pension only, 17 percent by a DC plan only, and 18 percent by both types of plans (Figure 1). By 2016, 7 percent had only a DB plan, 8 percent had both types of plans, and 37 percent relied on DC plans 
exclusively for their work-based pension. This transformation of the pension system has made benefits more flexible and portable_-virtues appreciated by many workers. But, it has also shifted risk and decision-making from employers to workers, fueling considerable anxiety about retirement preparation and retirement income being exposed to the volatility of investment returns.

As this transformation of the pension system has unfolded, numerous researchers have sought to understand the consequences for the adequacy of retirement income for older Americans. On the central question of the status of the adequacy of retirement income, the literature is divided. Some papers identify large shortfalls in the adequacy of retirement savings (Bernheim 1992; Munnell, Webb, and Delorme 2006; Munnell, Rutledge, and Webb 2014; Munnell, Hou, and Sanzenbacher 2018; Haveman et al. 2006; Munnell, Orlova, and Webb 2013). Others conclude that household financial preparation for retirement is in much better shape, and any shortfalls are largely concentrated among specific, more vulnerable groups, such as single retirees (Engen, Gale, and Uccello 1999; Sholz, Seshadri, and Khitatrakun 2006; Love, Smith, and McNair 2008).

\section{Defining Adequacy}

One of the methodological factors that differentiate these - and other — studies from each other is the way they define "adequacy." Adequacy is typically determined by comparing anticipated household income in retirement with pre-retirement income. Replacement rates are deemed "adequate" if they provide a smoothed level of consumption across a household's working life into retirement, with a potential step-down adjustment at the point of retirement. ${ }^{3}$ Another

\footnotetext{
${ }^{3}$ See Biggs and Springstead (2008) for a discussion of alternative standards of adequacy of replacement rates.
} 
approach to defining adequacy assumes declining levels of consumption over the retirement period, based on models in which households smooth the marginal utility of consumption over the life cycle; these models use assumptions on preference parameters and changes in consumption when children leave home (Sholz, Seshadri, and Khitatrakun 2006; Engen, Gale, and Uccello 1999).

The differences between these first two approaches to defining adequacy go a long way toward reconciling the competing pessimistic and more optimistic findings from the research on retirement adequacy. When Sholz, Seshadri, and Khitatrakun (2006) assume a more standard life-cycle rule that defines annual retirement consumption as a function of lifetime resources, they find that 49 percent of households have inadequate savings, compared with only 16 percent under their declining rate optimized path of consumption. Similarly, when Munnell, Rutledge, and Webb (2014) adjust the adequacy rules in the National Retirement Risk Index (NRRI) to incorporate the optimal rates of asset drawdown implied in Sholz, Seshadri, and Khitatrakun (2006), the share of households (heads aged 51 to 61) with inadequate retirement resources falls from 35 percent to 24 percent. When they also incorporate the assumption that Sholz, Seshadri, and Khitatrakun (2006) use regarding the decline in consumption after children leave the home, the share of households with inadequate savings falls further to 11.5 percent.

A third approach uses an external benchmark to indicate target levels of consumption in retirement (Wolff 2002; Haveman et al. 2006; Love, Smith, and McNair 2008). One implication of the replacement-rate and smoothed-consumption approaches to defining "adequacy" is that, because they are determined relative to the household's own income history, poor households that are able to maintain the same poverty-level consumption in retirement are considered to 
have "adequate" resources. Households with much higher absolute standards of living might be considered to have inadequate resources.

Most studies that employ external benchmarks to assess adequacy use the official poverty thresholds, which vary over time and by household composition. Use of the poverty thresholds, however, has been criticized because, detractors argue, they are too low $(\$ 14,507$ for an elderly couple in 2016) to represent a meaningful standard of well-being for retirees. Gould and Cooper (2013) use the Supplemental Poverty Measure (SPM), which reflects health-care costs and regional differences in cost of living. Mutchler, Li, and Xu (2016) develop an "Elder Index," which is based explicitly on costs faced by seniors and varies by household composition, homeownership status, and regional cost differences. These alternative benchmarks are much higher than the poverty threshold, thus resulting in larger shares of current and future retirees falling below "adequate" levels of retirement income. Hurd and Rohwedder (2011) use observed consumption paths over retirement from panel data (the Health and Retirement Study) as a benchmark, identifying adequacy among recent retirees as sufficient income to afford retirement consumption and still be able to leave a bequest. Although the official poverty thresholds are much lower than these alternative benchmarks, they have been produced consistently for decades and can be used to explore changes in adequacy over time.

This study does not take a stand on the optimal definition of adequacy and instead presents a variety of measures that allows one to piece together an overall picture of adequacy.

\section{Measurement of Retirement Income \& Assets}

Most research on retirement income adequacy uses data from the Health and Retirement Study (HRS). The HRS is a high-quality household survey of older Americans that includes a battery of 
questions on household income and resources. In recent years, researchers have been able to link the HRS to individual Social Security earnings histories and to employer-specific pension plans. Studies using the HRS either explore adequacy among current retirees (Hurd and Rohwedder 2011; Moore and Mitchell 1997) or use the survey’s self-reported expected pension and benefits income data to explore income adequacy for those about to retire (Engen, Gale, and Uccello 1999; Love, Smith, and McNair 2008).

The HRS offers many advantages to researchers in this field, but it has some limitations as well. Due to the survey design, the HRS cannot tell us anything about the savings or anticipated retirement adequacy among younger workers. Several studies using the HRS evaluate adequacy among workers as young as 51 years old (Munnell, Orlova, and Webb 2013; Gustman and Steinmeier 1999; Scholz, Seshardi, and Khitatrakun 2006). Ideally, however, retirement preparation starts much earlier in the life cycle. Also, because it does not include high-net-worth households, the HRS cannot be used to fully evaluate the implications of Social Security on wealth concentration. ${ }^{4}$

Several other studies explore retirement adequacy using the Survey of Consumer Finances (SCF). Because the SCF samples the entire age distribution, these studies are able to look at retirement income among younger cohorts of savers. Kennickell and Sunden (1997) use the ageearnings profile from one year of Current Population Survey (CPS) data to predict earnings histories of households whose heads are younger than 65 years old. ${ }^{5}$ Wolff $(2002,2007,2015)$ predicts earnings histories within the SCF using an in-sample estimation of future earnings based

\footnotetext{
${ }^{4}$ While the ability to match to Social Security earnings is extremely useful, not all respondents agree to the match, and researchers need to estimate earnings for the missing records. There is some evidence of bias introduced by the selection of respondents who agree to the match (Bricker and Engelhardt 2014).

${ }^{5}$ Given the early time period considered, Kennickell and Sunden (1997) show an equalizing effect on wealth distribution of DB and Social Security wealth, but not of DC wealth.
} 
on a simple human capital earnings regression in conjunction with respondent-provided currentand past-job information. These predicted retirement incomes are used to evaluate adequacy in several years of the SCF for cohorts that are younger (47 to 64 years olds [Wolff 2002, 2007] and 40 to 55 year olds [Wolff 2007]) than those evaluated using the HRS.

The National Retirement Risk Index (NRRI), developed by the Center for Retirement Research, also uses the SCF to evaluate retirement adequacy. The NRRI imputes earnings histories into the SCF through a statistical match with the linked HRS/Social Security earnings data. The NRRI calculates adequacy across the full age distribution. Since the HRS includes only workers in their 50s and older, several additional assumptions are needed to predict earnings histories and future earnings for younger workers.

All the above SCF studies use the self-reported DB pension responses in the SCF and rely on out-of-sample data to predict earnings histories for the purpose of calculating future Social Security benefits. This paper aims to improve on both of these solutions to measurement challenges in order to enhance our understanding of retirement preparation over the life cycle and across the distribution of household resources.

A final related area of the literature focuses on the adequacy of retirement income for individuals who have recently retired. Brady et al. (2017), for example, find that most individuals maintain a high replacement rate of pre-retirement income after they retire, but the authors acknowledge that there is variability across the income distribution. ${ }^{6}$ This strand of the literature uses panel tax data to follow the changes in income in pre-retirement and retirement years and is more focused on the contribution of the different types of retirement income (such as Social Security and

\footnotetext{
${ }^{6}$ Beshears et al (2019) come to a similar conclusion.
} 
pensions) to overall retirement income. Due to the research design and data source, these studies focus on individuals near retirement age and cannot examine the accumulation of assets before retirement.

\section{B. Wealth Distribution}

That wealth - particularly financial assets - is highly concentrated at the top of the distribution has long been acknowledged and, in fact, is the motivation for the unique sampling strategy employed in the Survey of Consumer Finances (SCF). Results from the 1989 SCF indicate that the top 1 percent of households held 16 percent of all income but 30 percent of net worth (Bricker at al. 2016). Most research exploring the distribution of wealth in the United States relies on the SCF (Bricker et al. 2016; Keister and Moller 2000; Wolff 1995; Kennickell 2006). Some wealth distribution research uses the Panel Study of Income Dynamics (PSID), which also includes questions on assets and debt (Quadrini 1999; Banks, Blundell, and Smith 2003; Fisher et al. 2016). These studies yield lower estimates of wealth concentration because the PSID does not adequately sample high-wealth households, and it does not ask about some asset types that are disproportionately held by the wealthy (Juster, Smith, and Stafford 1999; Pfeffer et al. 2016). The top 5 percent's wealth share for 1989 was 47 percent in the PSID, but 57 percent in the SCF (Wolff 2007).

Wealth is highly concentrated, and accurate measurement of its concentration is highly dependent on the use of data that include high-wealth households. The extent to which the concentration of wealth has risen over time, however, is in dispute. Analysis of net worth reported in the SCF suggests top-wealth shares have increased somewhat, with the top 1 percent's share climbing to 38 percent by 2016 (Bricker et al. 2017). In an alternative approach, Saez and Zucman (2016) use a capitalization model to predict wealth based on flows of capital 
income reported on federal income tax forms and rates of return estimated from the Federal Reserve Board's Financial Accounts of the United States and other macrodata sources. They find that wealth predicted from tax returns rises in much the same way as reported wealth does—with the top 1 percent's share climbing from 28 percent in 1989 to 39 percent in 2016.

Each of these studies improves our understanding of trends in the distribution of wealth, but neither uses a wealth concept that includes the implied asset value of Social Security benefits. Devlin-Foltz, Henriques, and Sabelhaus (2016) show that including improved measures of DB pension wealth results in somewhat lower measures of wealth concentration in the SCF, and we build directly on that work. The absence of Social Security from the discussion of wealth concentration is troubling for several reasons. Social Security benefits represent the singlelargest source of retirement income for more than 60 percent of retired households (Social Security Administration 2016). Because the accumulation of wealth to finance retirement is the dominant reason for saving, and Social Security may "crowd out" private savings or is the primary savings mechanism for many lower-income households, discussions of wealth distribution, especially in the context of economic policy, that do not include the value of Social Security are limited at best and potentially misleading.

\section{Data and Methods}

For the purposes of improving the measurement of wealth concentration and extending the research on retirement income adequacy to a younger cohort of households, we use the Survey of Consumer Finances (SCF) to develop an expanded measure of wealth that incorporates estimates of DB wealth as well as the asset value of Social Security among the 40- to 59-year-old population. We directly incorporate the work of Sabelhaus and Volz (2019), who impute the value of DB wealth to current workers in the SCF using labor market and pension plan 
characteristics in the survey along with high-quality external data on DB plan assets. In this section, we discuss the SCF and the methods we use in (1) estimating earnings histories of survey respondents, (2) calculating future Social Security benefits, and (3) aging-forward net worth reported in the SCF to the point of retirement.

Our research represents an improvement on work by others using the SCF to develop broader wealth measures for the purpose of assessing retirement adequacy (NRRI studies by Munnell et al. various years) or the distribution of wealth (Wolff various years). Both Wolff and Munnell et al. rely solely on self-reported information on pensions in the SCF to estimate DB wealth for future retirees, which results in levels of predicted pension wealth that are inconsistent with economy-wide pension assets. ${ }^{7}$ Following Sabelhaus and Volz (2019), we instead combine aggregate data on plan assets with the SCF survey data to estimate DB wealth of current workers. (See Section 3B below and Appendix A for additional details.) In calculating Social Security wealth of current workers, Wolff estimates in-sample human capital equations to predict future covered earnings, and Munnell at al. statistically match SCF workers with a standardized earnings trajectory based on linked HRS-Social Security earnings records. The static ageearnings profiles embodied in Wolff's approach fail to capture how workers' earnings evolve over time, an element we incorporate in our analysis using cohort earnings trajectories. (See Section 3C below for details on our approach.)

\section{A. The SCF}

\footnotetext{
${ }^{7}$ Wolff (various years) combines self-reported future pension coverage with an estimate of future earnings. The NRRI studies by Munnell et al. also make assumptions about declining generosity across cohorts and about future coverage for younger cohorts without DB pensions.
} 
The primary data source we use are the 10 waves of the triennial Survey of Consumer Finances (SCF) conducted from 1989 through 2016. Several features of the SCF make it appropriate for exploring retirement-income adequacy and the distribution of wealth. The survey collects detailed information about households' financial assets and liabilities, and has employed a consistent design and sample frame since 1989. As a survey of household finances and wealth, the SCF includes assets that are broadly shared across the population (bank savings accounts) as well as assets that are held more narrowly and are concentrated in the tails of the distribution (direct ownership of bonds).

To support estimates of a variety of financial characteristics as well as the overall distribution of wealth, the survey employs a dual-frame sample design. A national area-probability (AP) sample provides good coverage of widely held assets and debts. The AP sample selects household units with equal probability from primary sampling units that are chosen through a multistage procedure, which includes stratification by a variety of characteristics. Due to the concentration of assets and non-random survey response rates by wealth, the SCF also employs a list sample that is developed from statistical records derived from tax returns under an agreement with the IRS's Statistics of Income (SOI) program. ${ }^{8}$ This list sample consists primarily of households with a high probability of having high net worth. ${ }^{9}$ The SCF combines the observations from the AP and list samples through weighting, and the weighting design adjusts the samples separately using the information available for each one. The final weights are adjusted so that the combined

\footnotetext{
${ }^{8}$ See Bricker et al (2014) and Bricker et al (2017) for recent discussions of the sampling strategy, the list sample, and the weights used in the SCF. See Wilson and Smith (1983) and Internal Revenue Service (1992) for a description of the SOI file. The file used for each survey largely contains data from tax returns filed for the tax year two years before the year the survey takes place.

${ }^{9}$ For reasons related to cost control on the survey, the geographic distribution of the list sample is constrained to that of the area-probability sample.
} 
sample is nationally representative of the population and assets. ${ }^{10}$ These weights are used in all calculations.

The primary purpose of the SCF is to collect information about household balance sheets.

Among the items measured in the SCF is the value of all financial and nonfinancial assets, including residential and non-residential real estate and privately held businesses, reported by the respondent at the time of the interview. ${ }^{11}$ Questions on household debt reflect all types of debt, including credit cards, mortgage debt, student loans, business debts, and other miscellaneous forms of debt. ${ }^{12}$

\section{B. Defined Benefit Pension and Social Security Wealth}

One shortcoming of the SCF, with regard to measuring both retirement-income adequacy and wealth concentration, is the omission of current asset values of future DB pension payments and Social Security benefits. Respondents enrolled in DB pension plans are asked questions about expected future benefits. Many workers, particularly those further from retirement age, may have limited knowledge about their plans or future benefits, and so the information collected from these questions is not necessarily an accurate reflection of what the respondents will actually receive (Starr-McCluer and Sunden 1999).

\footnotetext{
${ }^{10}$ The SCF weights were revised in 1998 to incorporate home ownership rates by race (Kennickell 1999). Weights for earlier years were updated to reflect the revised methodology.

${ }^{11}$ Assets do not include - and the SCF does not collect - information on the value of DB pensions or the implied annuity value of future or current Social Security benefits of respondents.

12 The unit of analysis in the SCF is the "primary economic unit" (PEU), which refers to a financially dependent and related (by blood, marriage, or unmarried partners) group living together. This concept is distinct from both the household and family units employed by the US Census Bureau, but is conceptually closer to the latter, and throughout this paper PEUs are referred to as "families." Single individuals living alone are included and considered simply a "family" of one.
} 
Instead of relying fully on the expected future benefit responses provided by DB plan participants, we rely on the estimated DB pension wealth for SCF households developed by Devlin-Foltz, Henriques, and Sabelhaus (2016) and Sabelhaus and Volz (2019). Their approach assigns aggregate household sector DB assets from the Financial Accounts of the United States (FA) to both current and future beneficiaries using survey information on benefits currently received for those receiving payments, reported future payments for those with coverage from a past job, and wages and years in the plan for those not yet receiving benefits. The authors combine the survey information with real discount rates that fluctuate over time, cohort life tables, differential mortality estimates, and the assumption that current beneficiaries have first claim to DB plan assets. ${ }^{13}$ Devlin-Foltz, Henriques, and Sabelhaus (2016) find that inclusion of the implied assets from future pension benefits modestly reduces inequality in the distribution of wealth, but they do not include implied wealth from future Social Security benefits in their discussion of wealth distribution. To develop estimates of future Social Security benefits, and their implied asset value, we first need to estimate earnings histories (and projections) for respondents and their spouses in the SCF.

\section{C. Methodology for Estimating Earnings Profiles in the SCF Using CPS Cohorts}

To construct a full earnings history and projections of future earning for SCF respondents, we apply the growth in earnings over one's working life implied by the shape of the Current Population Survey (CPS) earnings estimates for individuals who are most similar to the SCF respondents based on birth year, occupation, education level, and sex.

\footnotetext{
${ }^{13}$ See Appendix A for more details on DB wealth estimation.
} 
From the 1989-2016 SCF data, we take respondents aged 40 to 59 (with spouses aged 30 to 65) at the time of the interview and use (1) information reported on current occupation, earnings, and tenure; (2) any retrospective information on occupation, earnings, or tenure; and (3) information reported on future work expectations. For each respondent and spouse, we estimate a full history of past and future earnings using regression analysis described below that rely on CPS data from 1964 through 2016.

Individuals are categorized into types by 21 possible birth-year cohorts (three-year cohorts from the 1924-1926 period through the 1984-1986 period), three education levels (less than high school, high school or equivalent, some college/degree), and five broad occupation categories ([1] management, professional, and related; [2] service; [3] sales and office; [4] construction, maintenance, production, transportation; and [5] self-employed from all occupations).

For some ages, we broaden the categories, defining an individual by education-occupation types (for men and women separately) instead of age when that person's birth-year cohort is not observed in the CPS at those ages. For instance, the youngest person whose earnings profile we want to estimate was born in 1986 and was 30 years old at the time of the 2016 SCF interview. The estimates will be based on earnings of those born in the 1984-1986 period who were as old as 32 in the 2016 CPS. To forecast earnings growth after age 32, we use coefficient estimates from the education-occupation model. Similarly, for the oldest birth year in the earliest (1989) SCF, 1924, we use the education-occupation model coefficients to fill in a person's earnings at each age before 1964. Those born between 1942 and 1951 are fully covered by the CPS.

For each person type $g$, we estimate the following regression on log income in the CPS:

$$
\ln \left(y^{g}\right)=\beta_{0}^{g}+\beta_{1}^{g} a g e+\beta_{2}^{g} a g e^{2}+\beta_{3}^{g} a g e^{3}+\beta_{4}^{g} a g e^{4}+\beta_{P T}^{g} \text { PartTime }
$$


and back out a person's individual effect, $\beta_{0 i}$, at the time of the SCF survey

$$
\beta_{0 i}=\ln \left(y_{i}\right)-\beta_{1}^{g} a g e_{i}+\beta_{2}^{g} a g e_{i}^{2}+\beta_{3}^{g} a g e_{i}^{3}+\beta_{4}^{g} a g e_{i}^{4}+\beta_{P T}^{g} \text { PartTime }_{i} .
$$

The individual effect in any year is a weighted average of the individual and group constants, $\beta_{0 i}$ and $\beta_{0}^{g}$, respectively, where we place more weight on the group average constant as we estimate periods further out from the reported income in the SCF. Specifically, the constant at time $t$ is $\beta_{i}^{W, t}=\rho^{t} \beta_{0 i}+\left(1-\rho^{t}\right) \beta_{0}^{g}$, where we set $\rho=0.85$.

To predict income, we then apply $\beta_{i}^{W, t}, \beta_{1}^{g}, \beta_{2}^{g}, \beta_{3}^{g}, \beta_{4}^{g}, \beta_{P T}^{g}$ for all ages for each individual. ${ }^{14}$ Anyone who reports a longest previous occupation type that is different from their current occupation will have different coefficients applied to the relevant years.

As an example, suppose we have a 2013 SCF respondent who is 50 years old at the time of the survey and reports current full-time earnings of $\$ 55,000$ in his current job of eight years. His reported longest previous job, which lasted 12 years, was in a different occupation and ended 14 years ago with his earning $\$ 35,000$. He reports having worked full-time every year since age 20 and expects to stop working at age 65 . The earnings history and earnings projection for this individual would look something like what is shown in Figure 2.

We assume when estimating an individual's future income that they will work until their expected retirement age, reported in the SCF, which will, of course, not be the case for everyone. The CPS income estimated for a person's type will account for relatively short periods of unemployment, as it includes total income for those who were not employed for the entire

\footnotetext{
14 There are 786 possible types: 630 of the more specific cohort-occupation-education-sex combinations, 126 cohort-education-sex combinations (applied when occupation is unclear), and 30 occupation-education-sex combinations (applied when estimating earnings if outside the ages the birth-year cohort is observed in the CPS or when some information is missing).
} 
previous year. However, with these measures, we will not be able to capture losses in income due to long-term unemployment, unanticipated early or partial retirement, or permanent labor force exit through disability, all of which could be modeled through shocks in future studies.

Our current SCF lifetime income estimates match the CPS well at younger ages, but they are relatively high at older ages (see Appendix Figures 1A and 1B for comparisons for two different birth-year cohorts of men). We attribute this difference primarily to lower income from partial retirement being captured in the CPS but not in the SCF retirement expectations and, to a lesser extent, to the differences in the SCF and CPS sample frames.

\section{D. Details of Social Security Benefits Calculations}

Armed with an earnings profile for each individual from ages 20 through 61, one can apply Social Security benefit calculations for each household. First, nominal earnings are indexed to age 60 , and the highest 35 are used to calculate each individual's averaged indexed monthly earnings (AIME). The AIME is transformed into a monthly payment using the primary insurance amount (PIA) formula and the cohort-specific actuarial adjustment. We assume all individuals begin receiving Social Security benefits at age 62, which provides a lower bound for total household Social Security wealth (SSW). Additional benefits are discounted to the survey year using a 3 percent real discount factor and survival rates that vary by cohort, marital status, race, and education (relying on cohort life tables from the Social Security Administration and differential mortality estimates from the Congressional Budget Office).

Wives (using the term generically for clarity but referring more broadly to secondary earners) are entitled to their own benefits (if eligible) but also spousal and survivor benefits. We assign spousal benefits to the household if they are expected to be greater than the wife's worker 
benefits at age 62. If the duration of the current marriages is less than 10 years when the wife reaches 62 , she does not receive spousal or survivor benefits. ${ }^{15}$

The measure of SSW used is net of expected future employee contributions. Thus, for every year (after the survey), we calculate expected tax payments of 6.2 percent and subtract the present value of all future contributions from the gross SSW measure calculated (as detailed above).

\section{E. Creating the Combined-Wealth Measure}

The combined-wealth measure that we analyze below incorporates (1) the implied wealth from Social Security benefits net of contributions and including projected earnings from future work up until the time of retirement, (2) wealth from DB pensions projected to the expected job end date, and (3) projected future wealth from all assets and debt measured directly in the survey.

To be consistent with the estimates of future Social Security wealth (which reflect expected benefits at age 62, not just those that had been accrued as of the interview date), we project the anticipated value of the SCF sample net worth, not including DB wealth, to age 62 (part [3] above). These projections are based on in-sample estimates of the growth paths of wealth from age 40 to 62 using all 10 SCF cross-sections (1989 through 2016). We categorize each household into one of nine groups based on its location in the distribution of "usual" income - an income concept included in the SCF that smooths away transitory fluctuations ${ }^{16}$ — and current wealth among households in each survey. ${ }^{17} \mathrm{We}$ then estimate age-wealth profiles separately for each of

\footnotetext{
${ }^{15}$ The SCF does not collect information about length of previous marriages, thus some individuals with more than one marriage will not be accurately assigned dependent benefits from a former spouse.

${ }^{16}$ See Ackerman and Sabelhaus (2012) for further discussion.

17 The categories are all combinations of the bottom 40 percent, next 40 percent, and top 20 percent for both income and wealth. Households were divided into these categories to estimate the growth in wealth for households showing the most similar wealth-accumulating behavior within their income group. The categories were kept relatively broad, however, to capture the group in which a household would be likely to remain over the ages of 40 to 62 . For the years 1995 through 2016, usual income is used to rank households. For the 1989 and 1992 surveys, which predate the usual income question, we use current income.
} 
the nine categories, pooling all surveys, and apply the growth rates from these profiles to project households' survey wealth to age 62 . Separate profiles are estimated for housing wealth, defined contribution (DC) pension wealth, and all other forms of wealth measured in the SCF. The implied annual growth rates of combined wealth for each of the nine income-wealth cohorts over the 40-62 age span are higher for the lowest wealth cohorts (Appendix Figure 2). Among middle- and high-wealth households, the growth rate of wealth is highest for those in the top 20 percent of both wealth and usual income. Because the annual rate of growth in wealth is higher at younger ages, and we discount the projected wealth back to the age when we observe households in the sample, the net effect of the wealth projections is substantially larger for younger households (Appendix Figure 3). ${ }^{18}$

We also project DB wealth to an individual's expected job ending date or age 59, whichever comes first. This brings DB wealth in line with both SSW and projected DC wealth to acknowledge that individuals may have many more years of accumulating benefits, and it allows us to better compare age groups over time. To do so, we back out of the Sabelhaus and Volz (2019) accrued DB wealth the "generosity factor" implied by the allocation. The generosity factor reflects a percentage of final wages given as a DB benefit for each year of service one accumulates. For example, in a plan with a 1 percent generosity factor, an individual with 30 years of service would receive 30 percent of their final wages as a DB benefit. With a generosity

\footnotetext{
${ }^{18}$ This approach is different from the one taken by Munnell, Rutledge, and Webb (2014) in measuring future wealth. As a part of constructing the NRRI, Munnell, Rutledge, and Webb (2014) measure, for distinct components of wealth, wealth-to-income ratios by age in the SCF. They calculate target age-specific savings rates-for 48 different household types based on income, composition, homeownership status, etc.- - that would be required for the households to achieve a level of wealth where post-retirement consumption is equal to consumption just before retirement. Making projections for each component separately, as is done to construct the NRRI, will not necessarily be an improvement for the analyses in this paper. Projections based on a single model of total net worth produced growth paths similar to those from the current approach of separate projections for housing, retirement, and remaining wealth. This results from households within a given income-wealth category having relatively similar compositions of net worth components.
} 
factor, one can project a final DB payment for each individual, given their projected wages.

Expected DB payments then are transformed into present discounted value as of the survey date.

The combined-wealth measure we analyze below combines the net present value of projected SCF net worth with projected DB wealth and expected future Social Security wealth.

\section{F. Retirement Preparation Concepts}

We use two simple measures of household preparation for retirement. The first is wealth-toincome ratio. It divides our expanded wealth concept by the current reported household income. The second is an annuity measure of wealth. We compare the estimated annuity amount with the poverty level for elderly households, either one- or two-person households depending on the marital status of the respondent. ${ }^{19} \mathrm{We}$ also calculate the share of the population falling below various multiples of the poverty threshold. For these two basic measures of retirement income adequacy, we explore trends over time for both age groups, 40 to 49 and 50 to 59 .

\section{Results}

In this section, we describe the results for both retirement income adequacy and wealth concentration using our combined-wealth measure. We show results over time for each SCF cross-section from 1989 through 2016, and for both the 40-49 and 50-59 age groups. We first show means, medians, and total levels of various wealth categories. Next, we show wealth-toincome ratios, followed by annuitized poverty measures. Then we calculate wealth-percentile ratios and concentration measures.

\footnotetext{
${ }^{19}$ Our annuity calculation is the same as that used by Love, Smith, and McNair (2008). We divide the present value of our combined-wealth measure (net worth, including DC wealth, plus the net present value of Social Security and DB pension wealth) by the actuarially fair price of an annuity. The price is the sum of the probabilities of surviving to advanced age levels for both respondent and, if present, spouse, and it also assumes a 3 percent discount rate.
} 
4A. Retirement Wealth and Combined Wealth

\section{A.i. Components of Retirement Wealth}

The average wealth in defined contribution (DC) plans held by both age groups has followed a familiar path, rising substantially in the years before the financial crisis, experiencing a period of stagnation, and then reaching a new peak in the 2016 survey. Among 50- to 59-year-olds, mean DC balances were $\$ 53,000$ in 1989 , rose to $\$ 164,000$ by 2007 , fell back to $\$ 146,000$ by 2013 , and rose to a new high of $\$ 177,000$ by 2016 (Figure 3, right panel). Mean DC balances are considerably lower for the 40-49 age group, starting at $\$ 35,000$ in 1989 and reaching $\$ 94,000$ in 2016 after hitting a plateau of about \$80,000 from 2001 through 2013 (Figure 3, left panel). As DC accounts were not introduced until the late 1970s, it is not surprising that average balances were low in 1989. The data indicate substantial preparation before age 40, but a considerable amount of retirement wealth accumulation is also taking place as households move closer to retirement.

For the 40-49 age group, mean DB wealth started at $\$ 90,000$ in 1989 , peaked in 2007 at $\$ 156,000$, and was $\$ 148,000$ in 2016 (Figure 3). Mean DB wealth for 50- to 59-year-olds was $\$ 278,000$ in 2001 and fell across the remaining waves, hitting $\$ 206,000$ in 2016. Some of the difference in DB wealth we observe between the two age groups is mechanical; the same future benefit has to be discounted further back in time for younger ages. In addition, DB coverage is lower for younger workers, particularly in later years.

Predicted Social Security wealth (SSW) accounts for the largest portion of retirement wealth for both age groups in almost all years. Mean SSW rose from \$127,000 in 1989 to \$150,000 in 2016 
among 40- to 49-year-olds, and it rose from $\$ 189,000$ to $\$ 238,000$ over the same period for 50 to 59-year-olds. SSW rises along with earnings growth in the working population, and it has fallen slightly for the older age group since the financial crisis. The broad growth in SSW, particularly in the 1990s, has come generally from two sources: higher real wages and increased labor force participation among women.

\section{A.ii. Combined-Wealth Measures}

It is well known that the financial crisis and housing market crash led to large losses of wealth throughout the economy. The bulk of these losses occurred in assets that are not specifically identified as forms of retirement saving (Bricker, Moore, and Thompson 2019). "Nonretirement" wealth here includes housing and other forms of financial and nonfinancial wealth, and it excludes DC and DB wealth and expected Social Security wealth.

For all comparisons going forward, non-retirement wealth, DC wealth, and housing wealth are projected to age 62, and for those in a DB plan, DB wealth is projected to the age they expect to separate from the firm for which they currently work. This puts all wealth measures on equal footing, allowing for better comparisons across age groups and over time. Due to life-cycle patterns, those in their 40s are expected (and shown, in Figure 3) to have less wealth accumulated for retirement. This does not, however, imply that the younger age group is less prepared for retirement.

The first set of bars in the left and right panels in Figure 4 shows that there is little change in non-retirement wealth over the full period, save for the short-lived run-up in housing wealth for the 40-49 age group leading up to the financial crisis; among 50- to 59-year-olds, non-retirement wealth increased more substantially. The middle set of bars, which combines non-retirement 
wealth with private retirement wealth, indicates that when DC and DB pensions are included, average wealth has increased over time for both age groups, although the growth has been substantially greater for 50- to 59-year-olds, particularly in 2016 in non-retirement wealth.

A similar pattern of growth in mean wealth persists once we incorporate projected net Social Security wealth. For 40- to 49-year-olds, mean combined wealth-including non-retirement wealth, DC and DB pension wealth, and net Social Security wealth—rose from $\$ 943,600$ in 1989 to $\$ 1.2$ million in 2007 , fell to $\$ 962,000$ by 2010 , and then partially recovered to $\$ 1$ million by 2016 (Figure 4). Among 50- to 59-year-olds, it rose from \$900,000 in 1989 to $\$ 1.5$ million in 2007, before falling to $\$ 1.3$ million in 2010, and recovering to almost \$1.5 million in 2016 .

Compared with the mean values, the median of the distribution of combined wealth rose less between 1989 and 2007 and fell relatively further after the financial crisis for both age groups (Table 1). Median combined-wealth levels were lower in 2016 than in 1989. Nearly all of the decrease in median combined wealth was due to the decline in non-retirement wealth (Table 2).

4A.iii. Combined Wealth across the distribution

The individual components of the combined-wealth measure have very different distributions. We explore the wealth levels at different points in the distribution in two ways. First, we look at the distribution for each of the wealth components- non-retirement wealth, DC and DB wealth, SSW - and combined wealth by age group and year. This highlights the fact that some components of combined wealth are distributed more equally than others.

Most households have no DB pension wealth, thus the values at the $10^{\text {th }}, 25^{\text {th }}$, and $50^{\text {th }}$ percentiles of DB pension wealth are zero for both age groups in 2016 (Table 1). Furthermore, more than one-quarter of households do not have any DC pension wealth. A majority of 
households do have a DC plan, but the median of the overall DC wealth distribution was just $\$ 4,200$ in 2016 among 40- to 49-year-olds and only $\$ 6,400$ among 50- to 59-year-olds. Both non-retirement wealth and Social Security wealth are far more broadly distributed than is either DB or DC wealth. Non-retirement wealth is very concentrated at the top, but-especially before the financial crisis-households at the bottom of the distribution do have some non-retirement wealth. Social Security is the only asset for which the lower tail of the distribution contains substantial wealth, with the $10^{\text {th }}$ percentile valued at $\$ 38,000$ in 2016 among 40 - to 49 -year-olds and $\$ 76,000$ among 50- to 59-year-olds. Of the combined-wealth measure components, Social Security is by far the most equally distributed.

We next rank households by combined-wealth distribution and show the levels of each of the wealth components for different points in this distribution (Table 2). These results highlight the wide variation of asset composition across households and clearly show that households at the bottom of the combined-wealth distribution rely heavily on Social Security; it accounts for almost all wealth at the $10^{\text {th }}$ percentile of the combined-wealth distribution for both age groups and more than half of the combined wealth of households at the $25^{\text {th }}$ percentile among 50 - to 59year-olds. The role of non-retirement wealth has fallen dramatically for households in the bottom quarter of the combined-wealth distribution since 1989.

To be sure, Social Security continues to account for a considerable portion of combined wealth even for households that are higher in the wealth distribution. Among 50- to 59-year-olds, Social Security wealth (SSW) accounts for approximately one-half of combined wealth at the median of the distribution and one-quarter at the $75^{\text {th }}$ percentile. At these points in the distribution, SSW remains dramatically larger than other forms of retirement wealth. It is only at the top of the distribution (the $90^{\text {th }}$ percentile here) that SSW is surpassed by DB and DC wealth. Social 
Security accounts for only 15 percent of combined wealth for households at the $90^{\text {th }}$ percentile of the distribution, for both age groups.

\section{B. Retirement Preparation Measures}

4B.i. Wealth-to-Income Ratios

Between 1989 and 2007, the combined-wealth-to-income ratios (WTI) generally rose at the upper part of the distribution (P75) and were generally flat at the middle of the distribution (median) for both the 40-49 and 50-59 age groups (Figures 5A and 5B). Toward the bottom of the distribution (P25), the combined WTI declined among the younger group across all years and was flat for the older age group. Following the financial crisis, median combined WTI fell for both groups. In 2007, it was 8.2 among 40- to 49 -year-olds and 9.4 among 50- to 59-year-olds. By 2016 , these ratios had fallen to 6.1 and 8.2 , respectively.

Following the financial crisis, the median private retirement (DB + DC) WTI saw only very small changes, dipping slightly for both age groups. These small declines suggest that, on balance, the changes in households' DB and DC account balances and the changes in their income were of similar magnitudes. Particularly for the 50-59 age group, Social Security wealth has counteracted the decline in the private retirement WTI. Thus, the overall retirement WTI (DC plus DB plus SSW) decreased less than private retirement wealth between 2007 and 2016. The decline in the combined WTI after 2007 is primarily due to a decline in non-retirement wealth.

4B.ii. Annuitized-Wealth-to-Poverty-Threshold Ratios

The mean annuitized-wealth-to-poverty-threshold ratio was mostly rising in the periods leading up to 2007, but it fell sharply in the wake of the financial crisis for both age groups. Among 50- 
to 59-year-olds, this indicator rose steadily, climbing from 6.0 to 8.9 between 1989 and 2007

(Figure 6A). By 2016, the annuitized-wealth-to-poverty-threshold ratio for this group was 8.3.

For 40- to 49-year-olds, movement in this indicator was similar, starting at 8.5 in 1989 and rising to 9.5 by 2007 before falling to 7.8 by 2016 .

Removing housing from the annuitized-wealth measure produces a smaller ratio that follows a parallel path with the original indicator, at least until 2007 (Table 3). The decline in the annuitized-wealth-to-poverty-threshold ratio after 2007 is attenuated somewhat once we exclude housing.

When we calculate the share of households that fall below various multiples of the poverty threshold, we see loosely consistent patterns, with the "below poverty" share falling in the early 1990s and rising sharply following the financial crisis. One important difference between the two approaches is that in the latter part of $1990 \mathrm{~s}$, when the mean annuity-to-poverty-threshold ratio was rising most, we see the below poverty share flattening out and starting to rise (Figure 6B). Among 50- to 59-year-olds, the share below 150 percent of the poverty threshold was 17.2 percent in 1989 and 14.4 percent at its low point in 2001 before climbing to 23.2 percent in 2016. More than 23 percent of 40- to 49-year-old households fell below 150 percent of the poverty threshold in 2016, compared with slightly less than 17 percent in 1989.

The poverty estimates reported here are similar to those found in earlier studies. With their annuitized-wealth measure, Haveman et al. (2006) show that the share of Social Security recipient households that fell below twice the federal poverty threshold was 22 percent in 1991; using the SCF we estimate that the annuitized wealth of 21.5 percent of 50- to 59-year-old households placed them below twice the poverty threshold in 1992 (Table 3). Love, Smith, and McNair (2008) calculate that among older households in the Health and Retirement Study 
(HRS), 18 percent had annuitized wealth that was below 150 percent of the poverty threshold during the 1998-2004 period; over that same period, we find that 16 percent of 50- to 59-yearold households were below 150 percent of the poverty threshold. Our findings do suggest, however, that poverty rates were considerably lower than those reported by Wolff (2002). Wolff reports a poverty rate of 19 percent in 1998 (among 47- to 64-year-olds) using an annuitized measure of expanded wealth. By contrast, we find a poverty rate of 8 percent among 50- to 59year-olds in $1998 .^{20}$

4C. Wealth Distribution

Looking at the ratios of the $90^{\text {th }}$ to the $50^{\text {th }}$ percentiles of the wealth distribution (P90/P50), we see inequality rising over the 1989-2016 period, and that inclusion of Social Security and retirement plan wealth has an impact on both the level of inequality and its trend. Among 40- to 49-year-olds, the P90/P50 ratio for non-retirement wealth rose from 2.9 in 1989 to 5.4 in 2016; among 50- to 59-year-olds, it climbed from 4.5 to 7.3 (Figure 7). The P90/P50 of combined wealth for the younger age group rose from 2.4 in 1989 to only 4.7 in 2016 . For 50- to 59-yearolds, the P90/P50 for combined wealth rose from 3.2 in 1989 to 5.7 in 2016.

When Social Security and retirement wealth are included, top shares become significantly lower and growth in top shares becomes slower. For the entire $40-59$ age range, we estimate that the top 5 percent of the distribution held 63 percent of non-retirement wealth, but only 51 percent of wealth including DB and DC pensions, and only 45 percent of combined wealth that also includes net Social Security wealth (Figure 8). Between 1989 and 2016, the top 5 percent's

\footnotetext{
${ }^{20}$ Differences between our estimates and those of Wolff could be due to methodological differences described earlier (his use of in-sample data to estimate life-time earning histories in the SCF or his use of in-sample data to estimate DB pension wealth) or other differences in the treatment of the data, for example his decision to exclude vehicles from a household's balance sheet, but to retain the debt related to those vehicles.
} 
share of non-retirement wealth rose 22 percentage points, while its share of combined wealth rose 13 percentage points. ${ }^{21}$

\section{Conclusion}

We create a new combined measure of wealth that adds defined benefit (DB) pension wealth and Social Security wealth to the typical wealth measure. We use this new combined-wealth measure to analyze the retirement preparation for households near retirement (50 to 59 years old) as well as a younger group of households (40 to 49 years old). The results show that a substantial number of households in both groups have expected incomes that are inadequate, based on the annuitized-wealth-to-poverty-threshold measure. Furthermore, the share of households in both age groups with predicted retirement incomes that are below the poverty level has risen sharply since the Great Recession, highlighting the lingering effects on household retirement preparations.

In terms of analyzing wealth concentration, using the combined measure of wealth results in a level that is lower than that when using the typical measure of wealth in all years. Wealth concentration is also rising slower, according to analysis involving the combined-wealth measure, evidence of the importance of including DB and Social Security wealth in discussions of wealth inequality and economic well-being.

\footnotetext{
${ }^{21}$ Estimates for the top 10 percent's share for the full sample and the top 5 percent's and top 10 percent's for each age group can be found in Appendix Table 6.
} 
Figure 1. Trends in Plan Participation among 40- to 59-Year-Old Household Heads

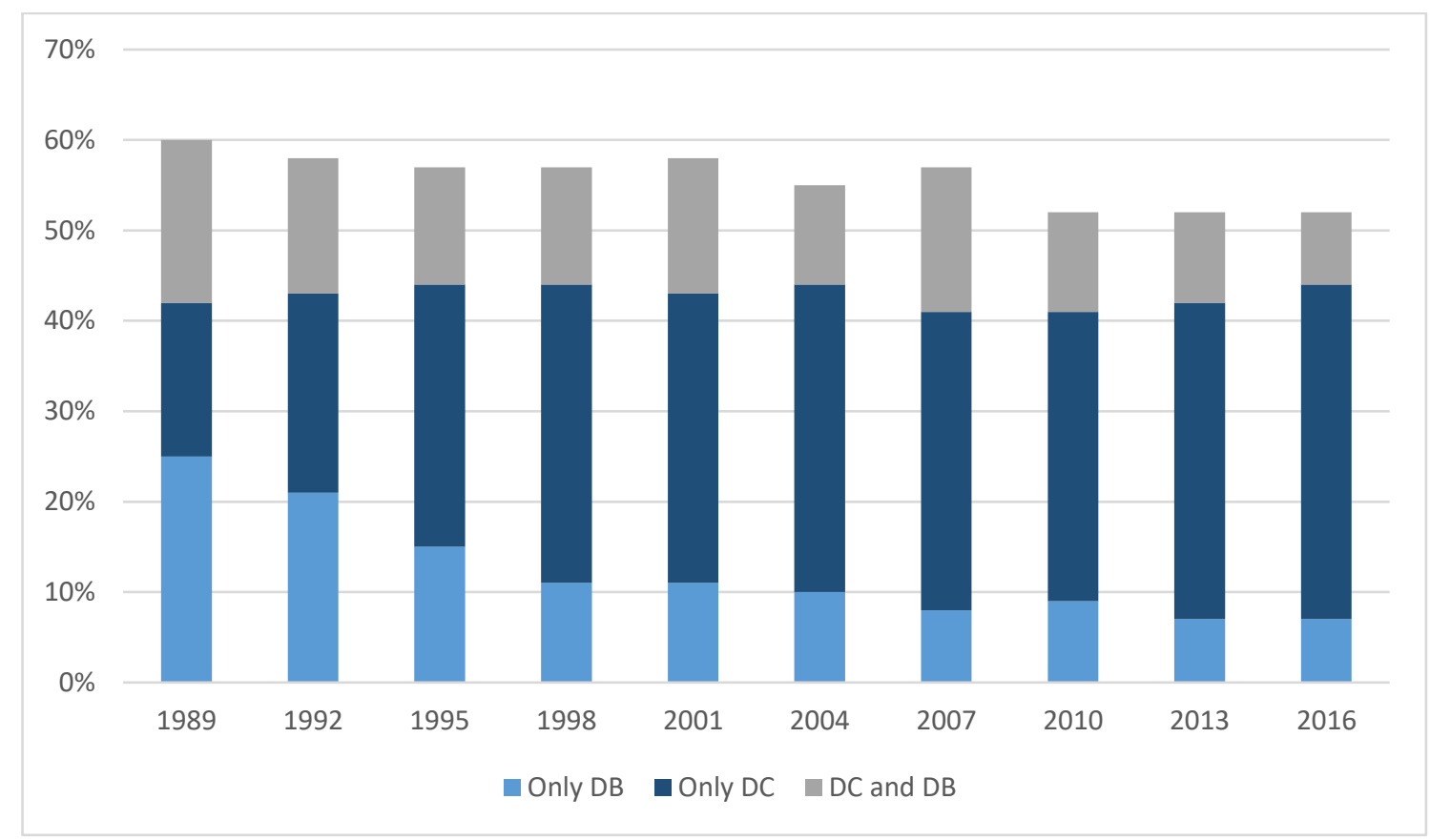

Figure 2. Construction of Earnings History for Hypothetical Household: 50-Year-Old Middle-Income Earner

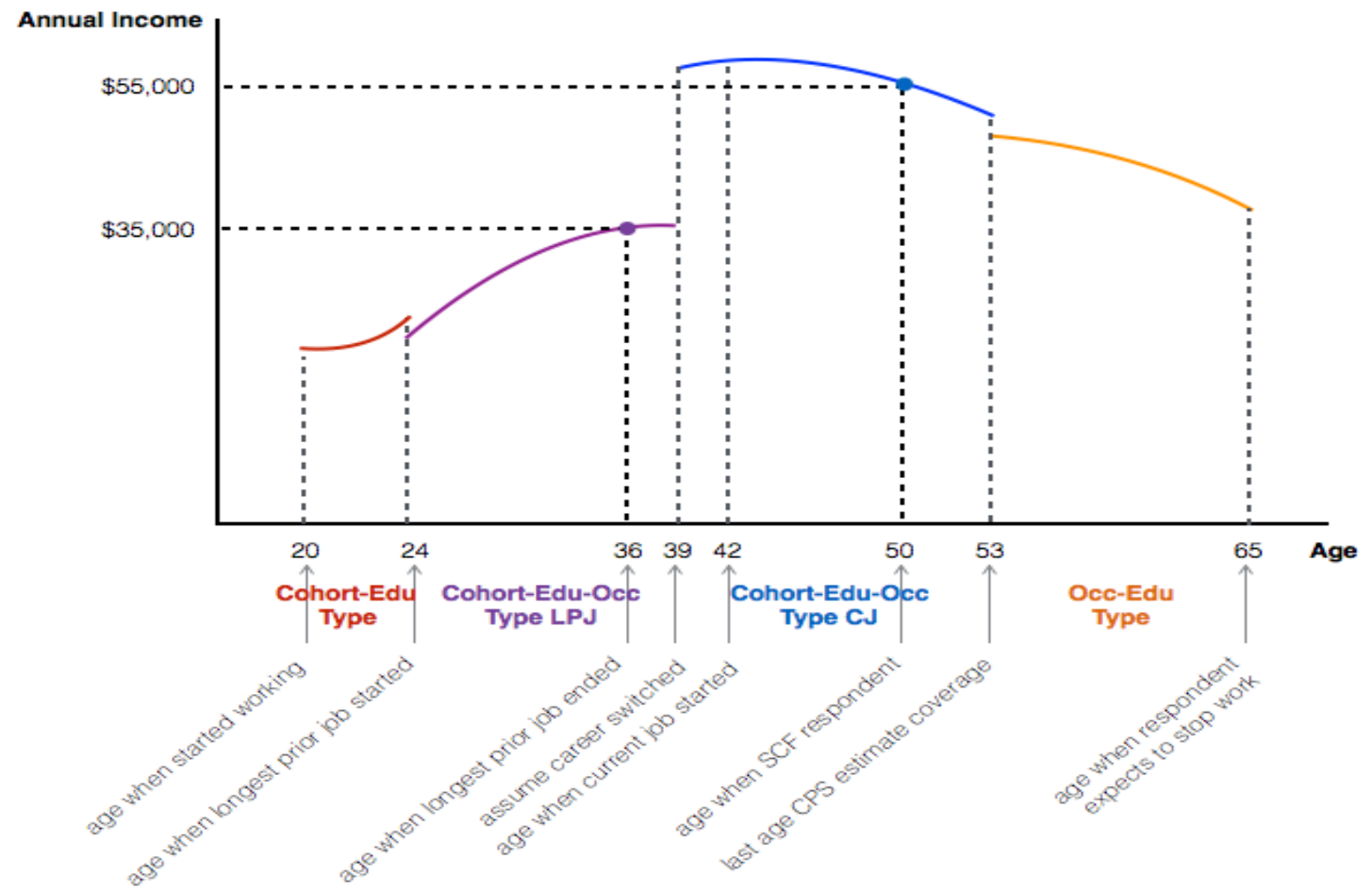


Figure 3. Mean Retirement Wealth by Type, Age Group, and Year (\$ Thousands)

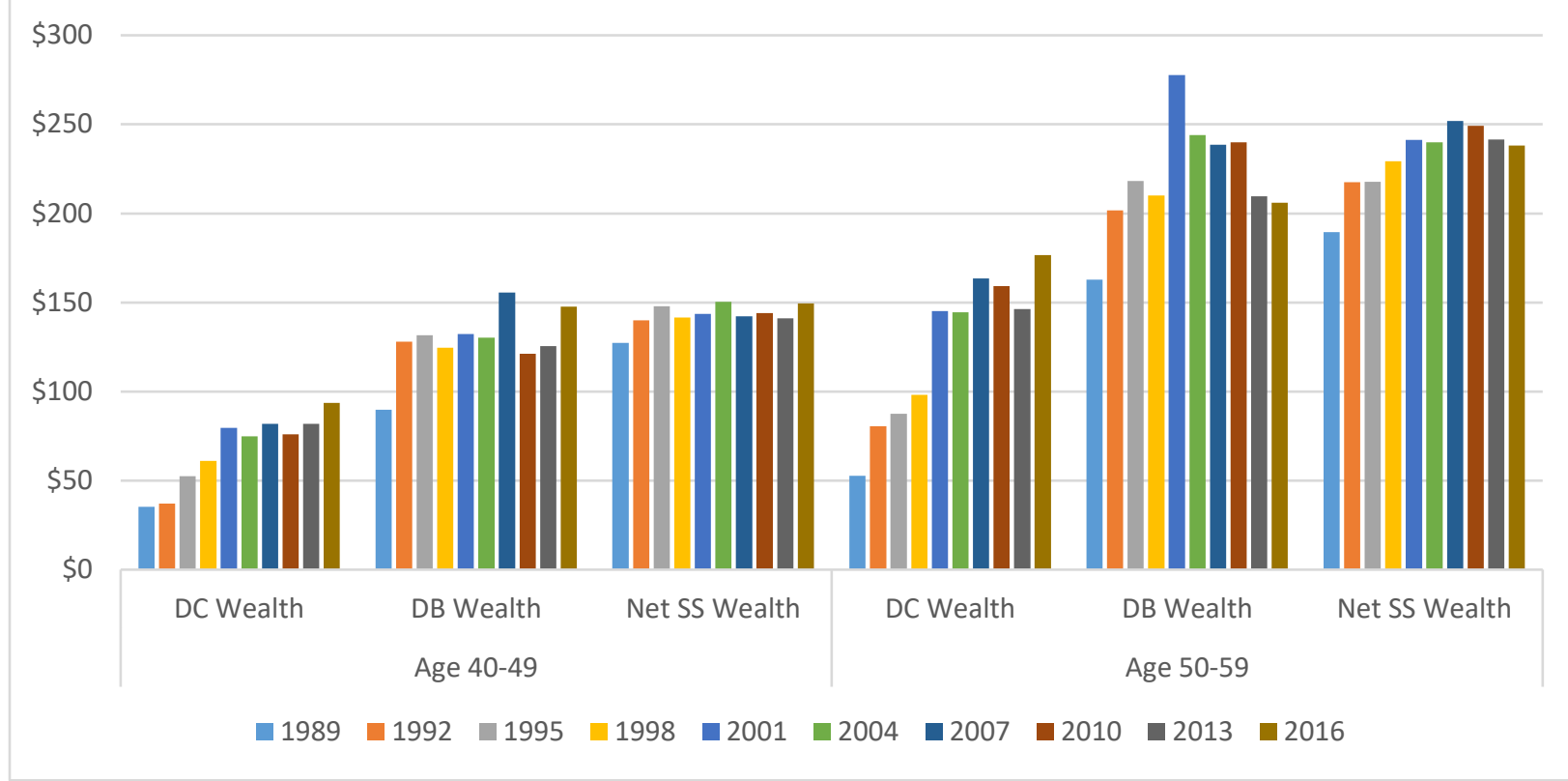

Note: DC and DB wealth are values as of the survey date. Net SS wealth is future stream of projected benefits at age 62 , discounted back to age at time of survey.

Figure 4. Mean Wealth by Wealth Concept, Year, and Age Group (\$ Thousands)

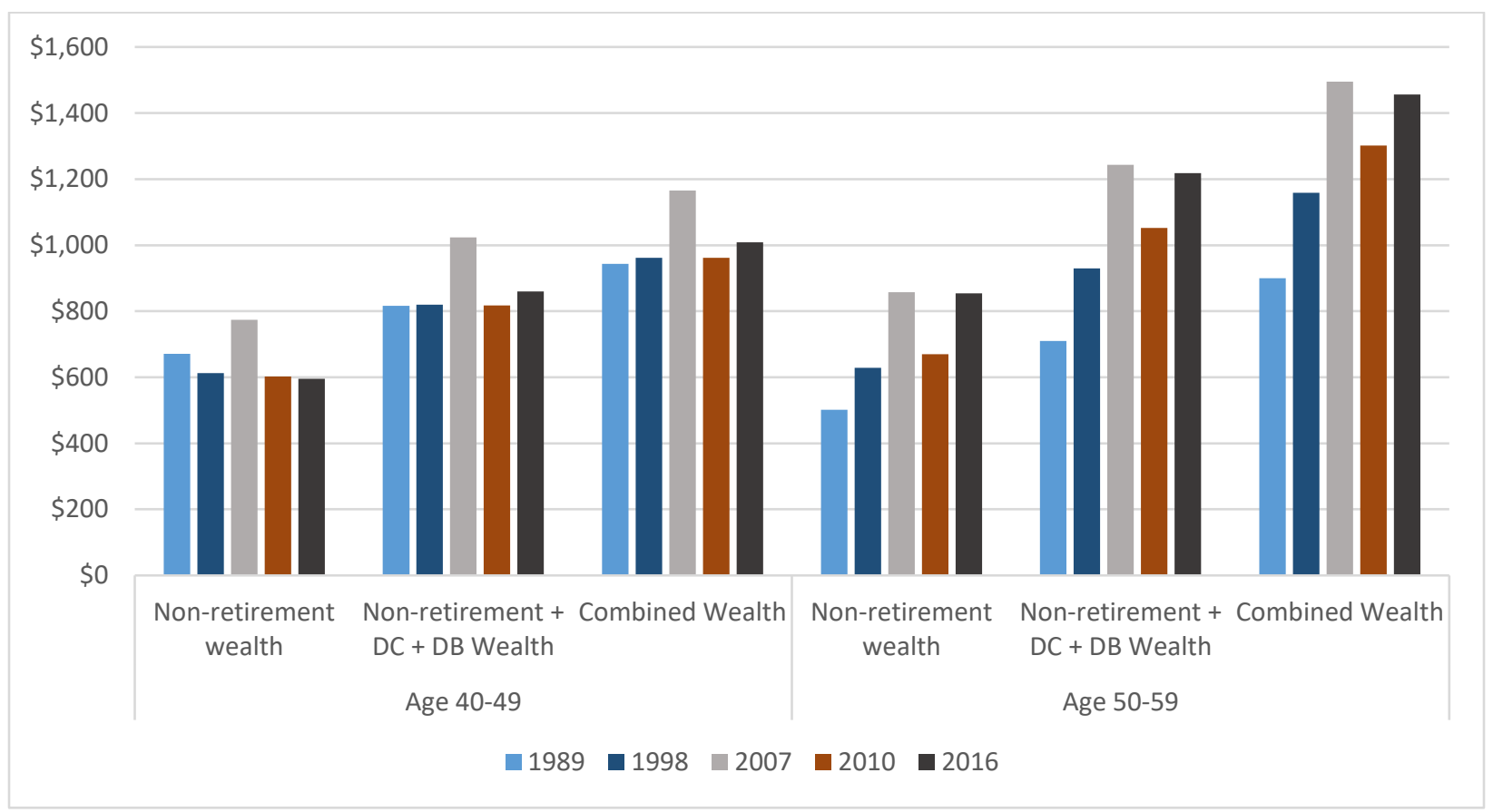

Note: Non-retirement wealth, DC wealth, and DB wealth are projected values, as described in the text. Net SS wealth is future stream of projected benefits at age 62 , also discounted back to age at time of survey. 
Figure 5. Wealth-to-Income Ratios (Median, P25, and P75) by Year, Wealth Concept, and Age Group

\section{A. 40- to 49-Year-Old Household Heads}

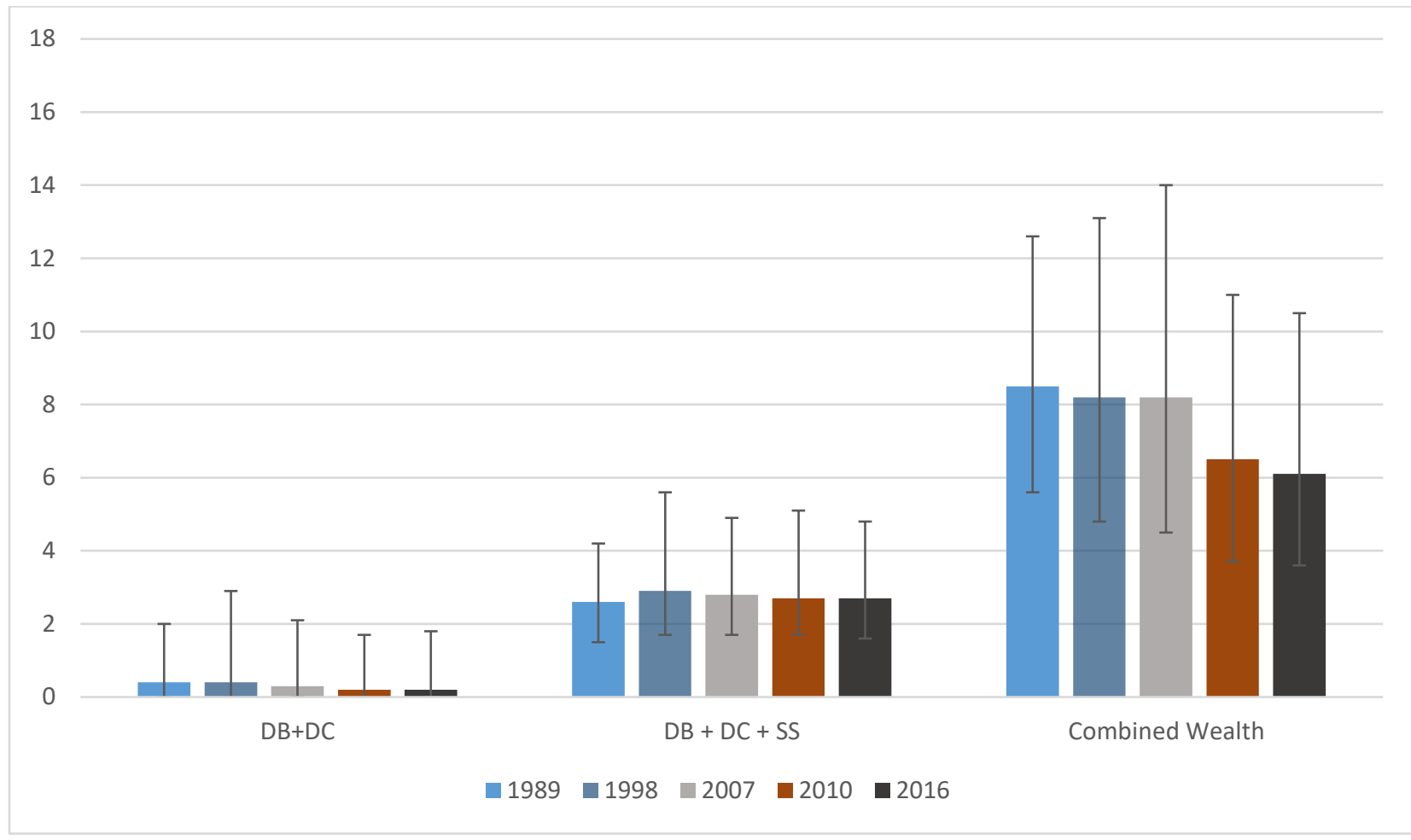

5B. 50- to 59-Year-Old Household Heads

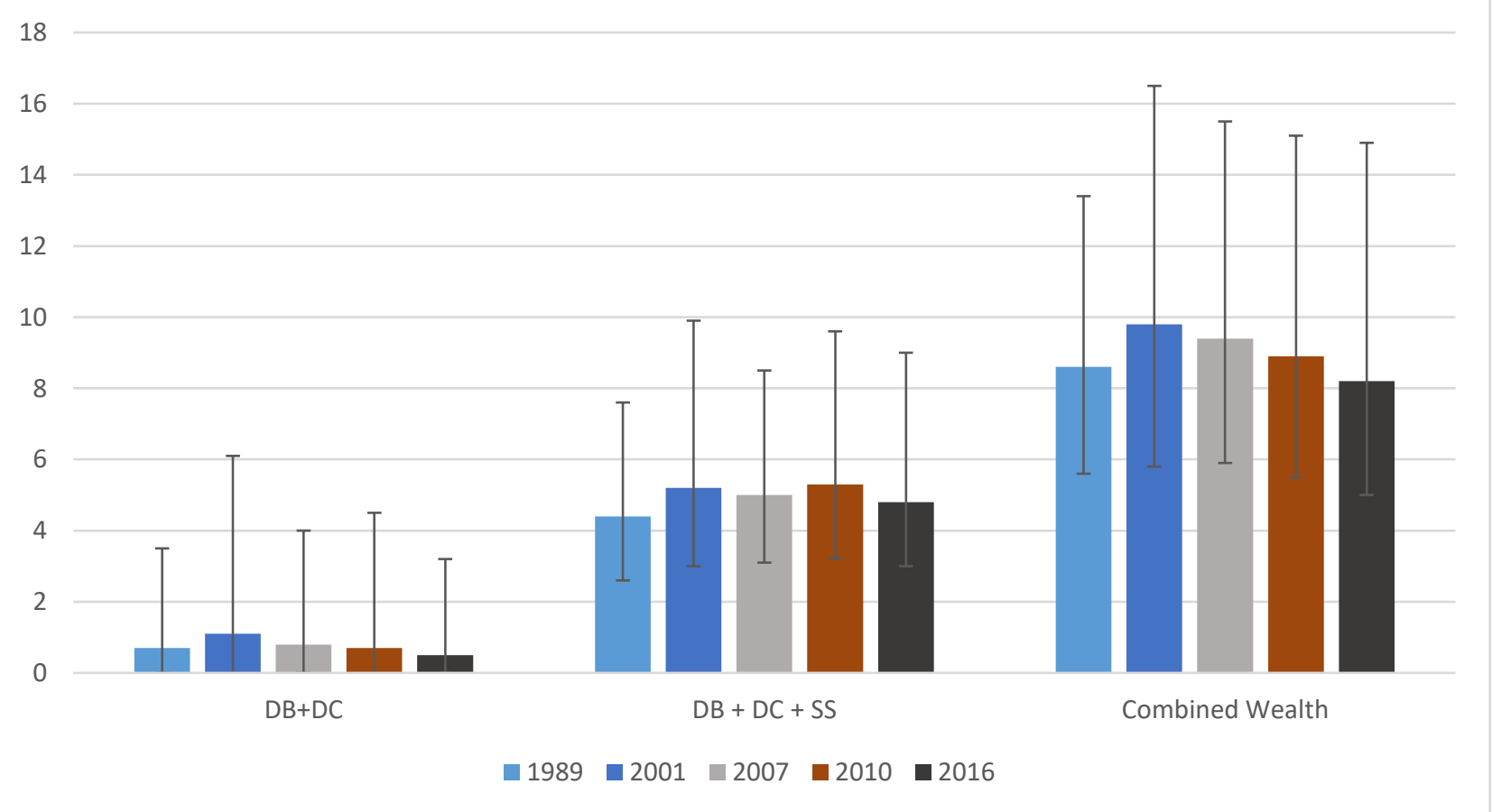


Figure 6. Annuitized Stream of Combined-Wealth-to-Poverty Ratio

\section{A. Mean Ratio}

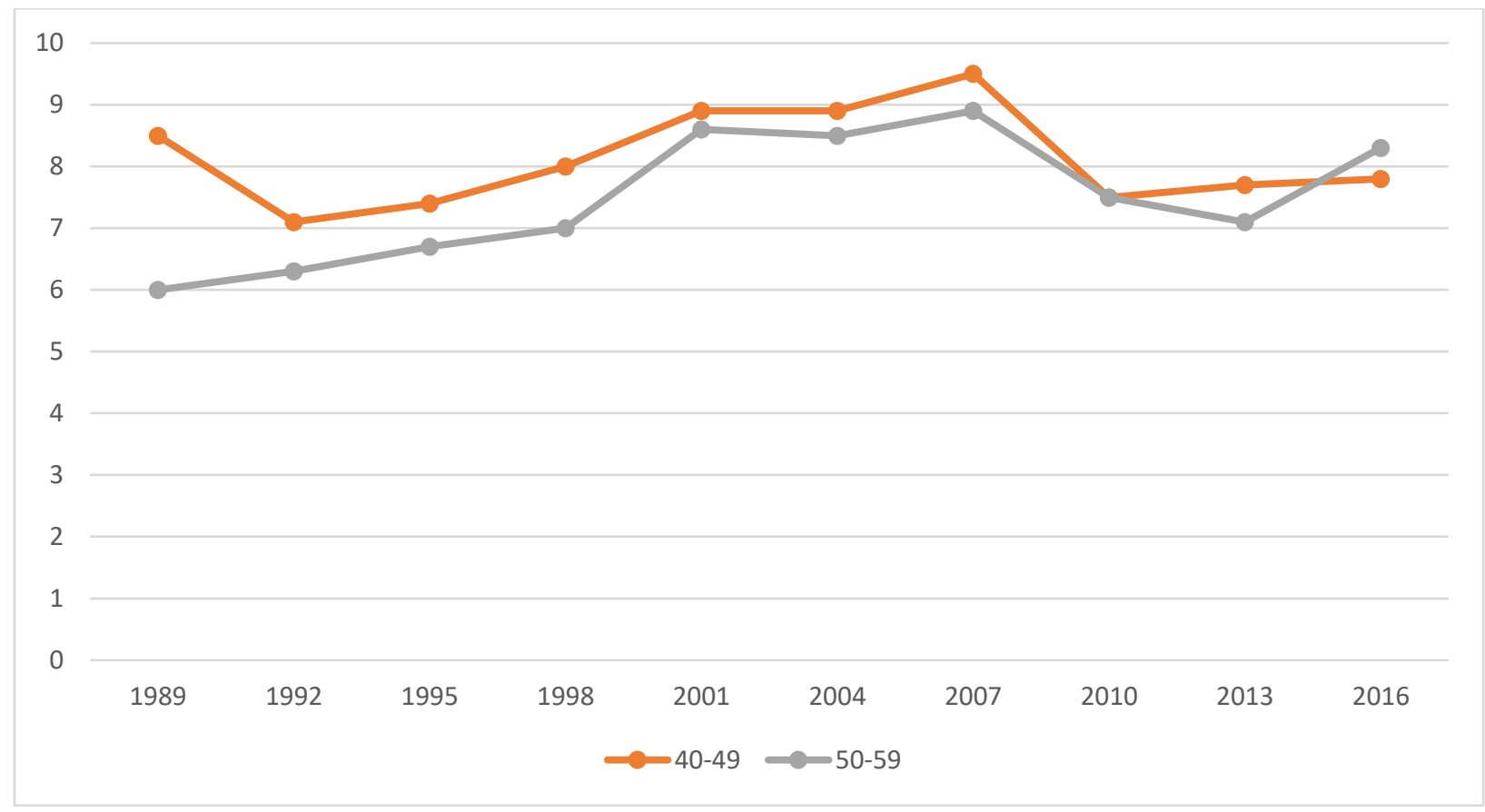

6B. Share of Households with Annuitized Combined Wealth below 150\% Poverty Threshold

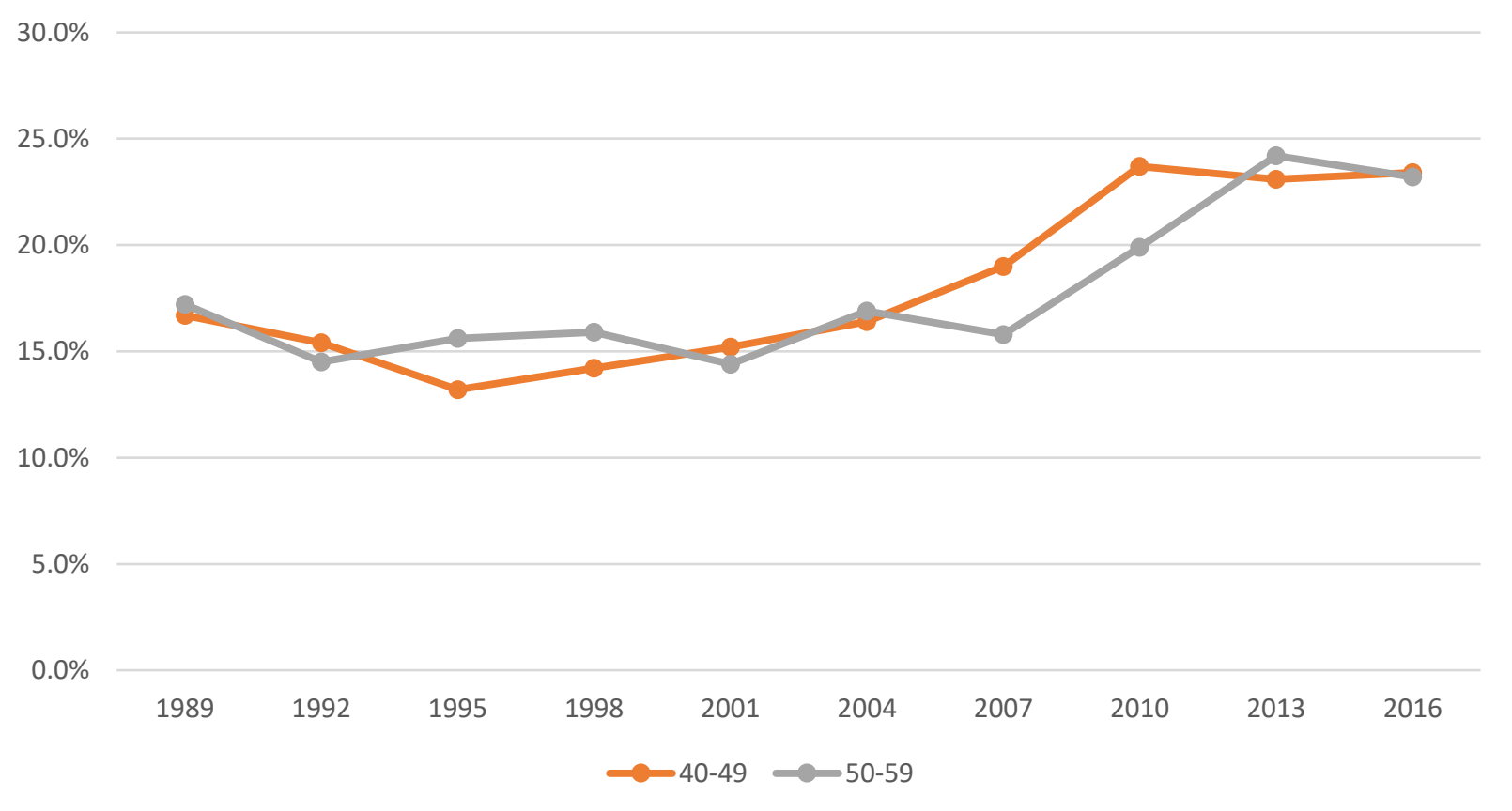


Figure 7. Distribution of Wealth by Concept, Year, and Age Group:

Ratio of $90^{\text {th }}$ Percentile to Median

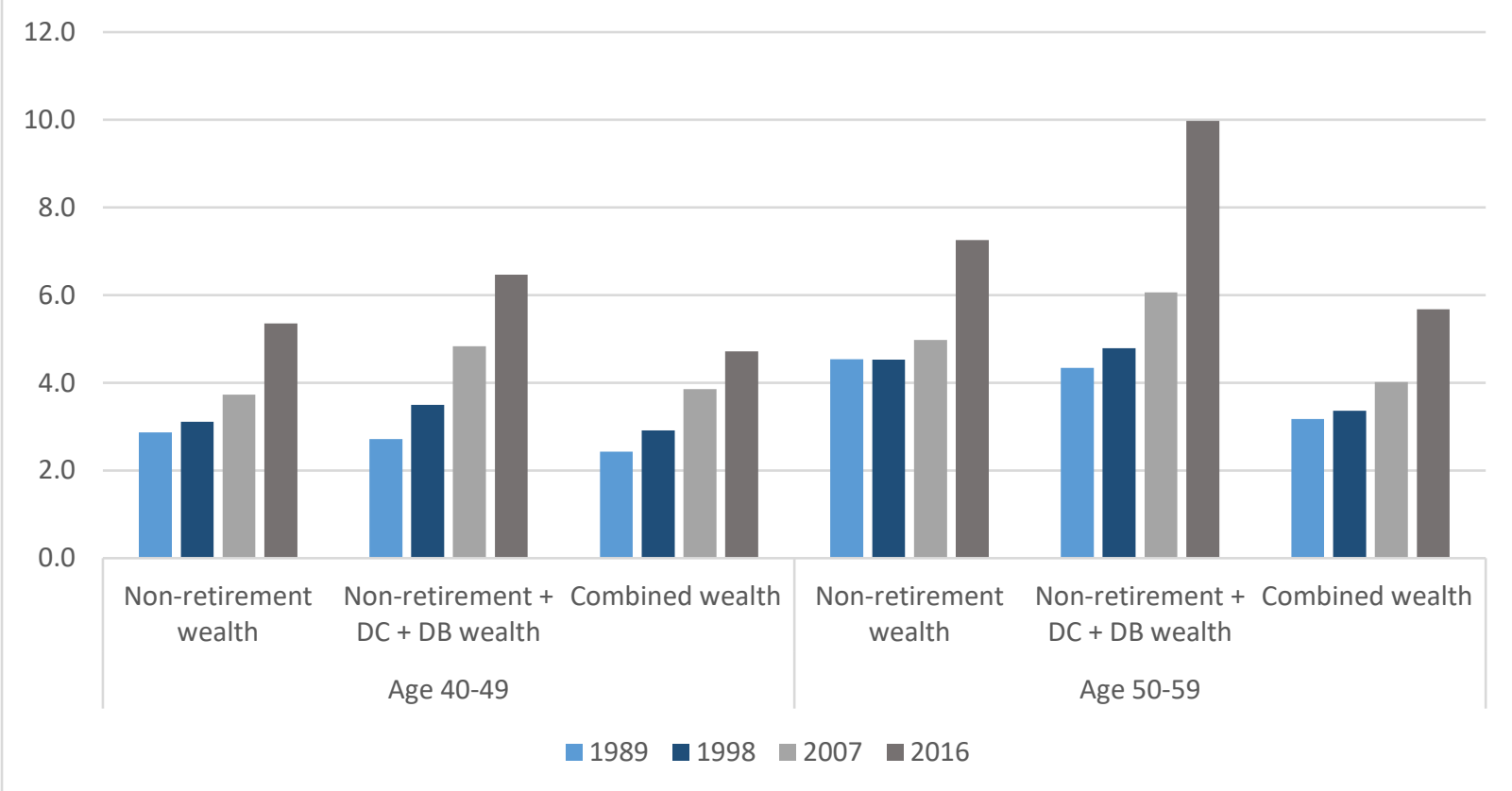

Figure 8. Top 5 Percent's Wealth Share by Wealth Concept—Ranked Separately by Wealth Concept for 40- to 59-Year-Olds

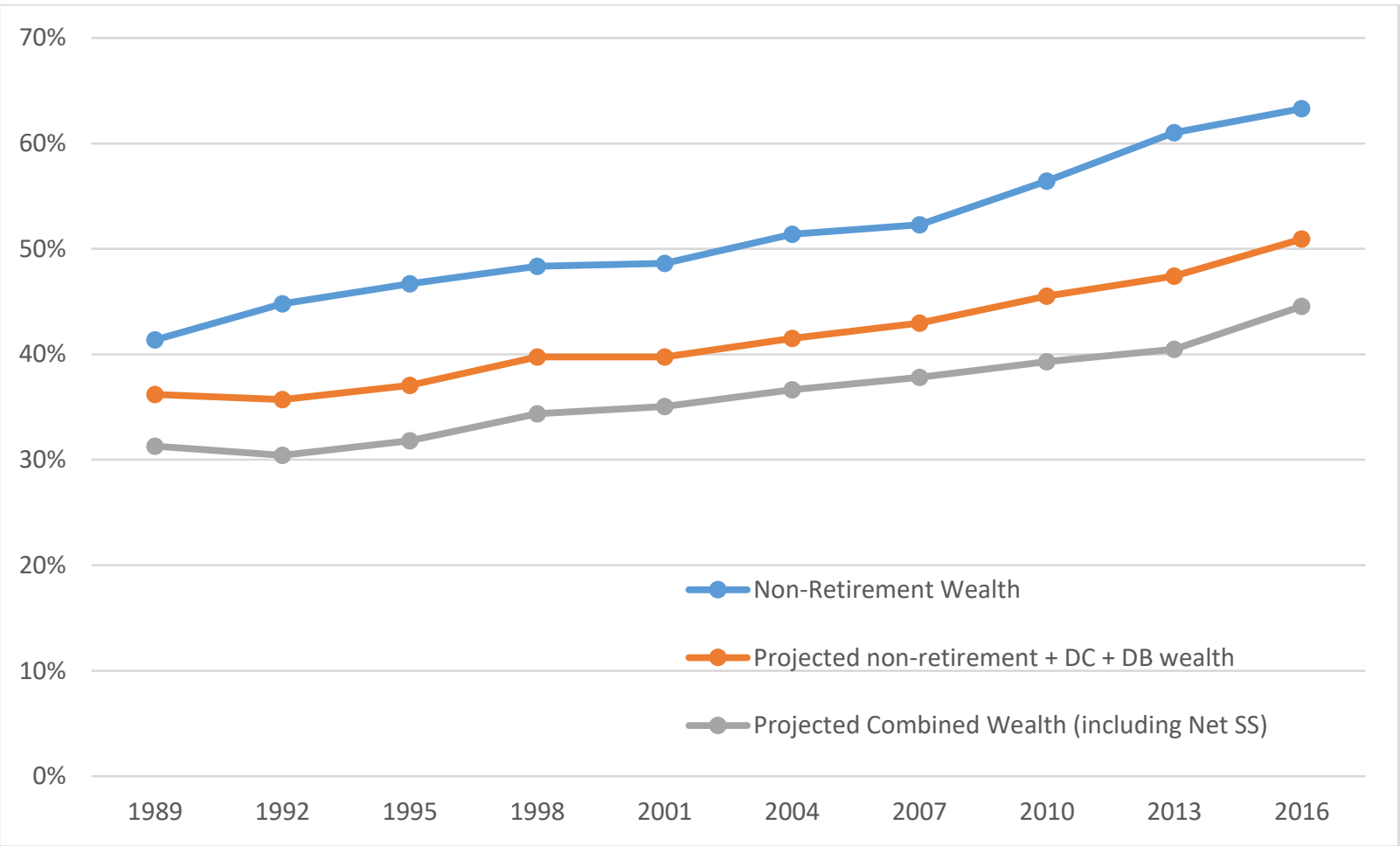


Table 1 Distribution of Combined-Wealth Components by Age Group, 1989, 1998, 2007, and 2016, Real 2016 (thousands)

\begin{tabular}{|c|c|c|c|c|c|c|c|c|c|c|c|}
\hline & \multirow[t]{2}{*}{ Age Group: } & \multicolumn{5}{|c|}{$40-49$} & \multicolumn{5}{|c|}{$50-59$} \\
\hline & & $\begin{array}{l}\text { Non- } \\
\text { retirement } \\
\text { Wealth }\end{array}$ & $\begin{array}{l}\text { DC } \\
\text { Wealth }\end{array}$ & $\begin{array}{l}\text { DB } \\
\text { Wealth }\end{array}$ & $\begin{array}{l}\text { Net } \\
\text { SSW }\end{array}$ & $\begin{array}{l}\text { Combined } \\
\text { Wealth }\end{array}$ & $\begin{array}{l}\text { Non- } \\
\text { retirement } \\
\text { Wealth }\end{array}$ & $\begin{array}{l}\text { DC } \\
\text { Wealth }\end{array}$ & $\begin{array}{l}\text { DB } \\
\text { Wealth }\end{array}$ & $\begin{array}{l}\text { Net } \\
\text { SSW }\end{array}$ & $\begin{array}{l}\text { Combined } \\
\text { Wealth }\end{array}$ \\
\hline \multirow[t]{4}{*}{ p10 } & 1989 & 2.1 & 0.0 & 0.0 & 30.0 & 78.6 & 6.4 & 0.0 & 0.0 & 42.2 & 105.5 \\
\hline & 1998 & 16.1 & 0.0 & 0.0 & 41.3 & 96.4 & 3.2 & 0.0 & 0.0 & 74.6 & 140.4 \\
\hline & 2007 & 0.7 & 0.0 & 0.0 & 35.0 & 60.3 & 4.4 & 0.0 & 0.0 & 84.9 & 147.1 \\
\hline & 2016 & -0.1 & 0.0 & 0.0 & 37.9 & 69.3 & 0.3 & 0.0 & 0.0 & 75.5 & 99.0 \\
\hline \multirow[t]{4}{*}{ p25 } & 1989 & 157.0 & 0.0 & 0.0 & 61.4 & 312.8 & 109.3 & 0.0 & 0.0 & 101.1 & 273.8 \\
\hline & 1998 & 139.4 & 0.0 & 0.0 & 69.0 & 292.3 & 79.6 & 0.0 & 0.0 & 119.1 & 303.4 \\
\hline & 2007 & 106.4 & 0.0 & 0.0 & 63.7 & 233.8 & 89.6 & 0.0 & 0.0 & 126.8 & 315.8 \\
\hline & 2016 & 35.1 & 0.0 & 0.0 & 72.2 & 174.1 & 30.8 & 0.0 & 0.0 & 118.6 & 228.2 \\
\hline \multirow[t]{4}{*}{ p50 } & 1989 & 395.7 & 0.0 & 0.0 & 118.0 & 638.6 & 219.6 & 0.6 & 2.0 & 178.9 & 571.0 \\
\hline & 1998 & 315.5 & 3.8 & 0.0 & 130.0 & 595.0 & 201.0 & 4.2 & 0.0 & 221.1 & 629.5 \\
\hline & 2007 & 337.8 & 5.6 & 0.0 & 130.9 & 623.7 & 255.2 & 16.3 & 0.0 & 233.2 & 746.9 \\
\hline & 2016 & 194.1 & 4.2 & 0.0 & 141.8 & 463.2 & 141.8 & 6.4 & 0.0 & 206.6 & 492.6 \\
\hline \multirow[t]{4}{*}{ p75 } & 1989 & 688.0 & 14.5 & 121.1 & 200.9 & $1,043.7$ & 426.5 & 35.3 & 234.5 & 276.0 & $1,034.1$ \\
\hline & 1998 & 599.7 & 56.6 & 82.1 & 211.4 & $1,084.0$ & 475.5 & 56.9 & 231.7 & 334.6 & $1,234.9$ \\
\hline & 2007 & 714.4 & 72.7 & 0.0 & 215.8 & $1,237.7$ & 638.4 & 113.8 & 148.2 & 373.2 & $1,484.5$ \\
\hline & 2016 & 479.5 & 76.0 & 0.0 & 227.0 & $1,030.8$ & 372.5 & 91.6 & 44.6 & 344.2 & 1,233.1 \\
\hline \multirow[t]{4}{*}{ p90 } & 1989 & $1,134.7$ & 86.3 & 283.5 & 239.5 & $1,551.1$ & 996.6 & 118.2 & 542.1 & 343.5 & $1,812.4$ \\
\hline & 1998 & 982.3 & 198.6 & 503.6 & 270.2 & $1,734.3$ & 910.6 & 223.9 & 748.0 & 399.9 & $2,115.7$ \\
\hline & 2007 & $1,259.8$ & 292.3 & 539.7 & 272.6 & $2,404.5$ & $1,270.9$ & 394.7 & 749.6 & 463.3 & $3,000.7$ \\
\hline & 2016 & $1,038.8$ & 415.3 & 463.5 & 288.0 & $2,184.7$ & $1,029.2$ & 439.6 & 690.6 & 461.7 & $2,796.8$ \\
\hline
\end{tabular}

Note: Each column ranks households by wealth component. 
Table 2. Wealth Levels at Points of the Non-retirement + DB + DC Wealth Distribution, by Age Group, 1989, 1998, 2007, and 2016, Real 2016\$ (thousands)

\begin{tabular}{|c|c|c|c|c|c|c|c|c|c|c|c|}
\hline \multirow[b]{2}{*}{$\begin{array}{l}\text { Percentile of } \\
\text { Combined } \\
\text { Wealth }\end{array}$} & \multirow{2}{*}{$\begin{array}{c}\text { Age Group: } \\
\\
\text { Year } \\
\end{array}$} & \multicolumn{5}{|c|}{$40-49$} & \multicolumn{5}{|c|}{$50-59$} \\
\hline & & $\begin{array}{c}\text { Non- } \\
\text { retirement } \\
\text { Wealth }\end{array}$ & $\begin{array}{c}\text { DC } \\
\text { Wealth }\end{array}$ & $\begin{array}{c}\text { DB } \\
\text { Wealth }\end{array}$ & $\begin{array}{l}\text { Net } \\
\text { SSW }\end{array}$ & $\begin{array}{c}\text { Combined } \\
\text { Wealth }\end{array}$ & $\begin{array}{l}\text { Non- } \\
\text { retirement } \\
\text { Wealth }\end{array}$ & $\begin{array}{c}\text { DC } \\
\text { Wealth }\end{array}$ & $\begin{array}{c}\text { DB } \\
\text { Wealth }\end{array}$ & $\begin{array}{l}\text { Net } \\
\text { SSW }\end{array}$ & $\begin{array}{c}\text { Combined } \\
\text { Wealth }\end{array}$ \\
\hline \multirow[t]{4}{*}{ p10 } & 1989 & 10.3 & - & - & 50.1 & 78.6 & 19.0 & - & - & 65.9 & 105.5 \\
\hline & 1998 & 17.2 & - & - & 65.4 & 96.4 & 15.7 & - & - & 95.6 & 140.9 \\
\hline & 2007 & 3.0 & - & - & 50.5 & 61.6 & 15.1 & - & - & 104.3 & 147.1 \\
\hline & 2016 & 1.5 & - & - & 58.0 & 69.4 & 4.0 & - & - & 86.6 & 99.0 \\
\hline \multirow[t]{4}{*}{$\mathrm{p} 25$} & 1989 & 183.2 & - & - & 77.6 & 315.4 & 139.9 & - & - & 120.8 & 276.7 \\
\hline & 1998 & 183.2 & 0.5 & - & 81.7 & 292.5 & 108.3 & - & - & 140.7 & 303.6 \\
\hline & 2007 & 118.7 & - & - & 78.0 & 233.8 & 110.9 & 5.2 & - & 162.2 & 315.8 \\
\hline & 2016 & 52.7 & - & - & 94.3 & 174.3 & 47.5 & - & - & 141.3 & 228.2 \\
\hline \multirow[t]{4}{*}{ p50 } & 1989 & 419.3 & 1.3 & 21.6 & 140.7 & 639.4 & 233.7 & 1.4 & 44.3 & 215.7 & 571.3 \\
\hline & 1998 & 357.6 & 3.0 & - & 167.3 & 595.0 & 243.8 & 8.1 & - & 264.7 & 629.5 \\
\hline & 2007 & 377.8 & 23.0 & - & 165.6 & 623.8 & 293.7 & 38.4 & - & 301.7 & 747.6 \\
\hline & 2016 & 241.9 & 7.1 & - & 173.2 & 463.5 & 151.9 & 15.5 & - & 271.7 & 492.6 \\
\hline \multirow[t]{4}{*}{ p75 } & 1989 & 668.8 & 14.0 & 102.2 & 181.4 & $1,045.2$ & 442.5 & 23.3 & 299.8 & 270.3 & $1,039.9$ \\
\hline & 1998 & 611.0 & 39.1 & 50.5 & 183.2 & $1,084.4$ & 447.5 & 31.9 & 301.2 & 328.0 & $1,237.1$ \\
\hline & 2007 & 826.2 & 60.6 & - & 201.8 & $1,237.7$ & 637.2 & 97.9 & 63.6 & 344.9 & $1,488.5$ \\
\hline & 2016 & 480.7 & 46.3 & - & 206.5 & $1,030.8$ & 380.6 & 106.8 & 45.6 & 306.7 & $1,235.9$ \\
\hline \multirow[t]{4}{*}{ p90 } & 1989 & $1,134.7$ & 12.5 & 133.0 & 196.6 & $1,564.7$ & 694.9 & 68.2 & 616.8 & 303.4 & $1,812.4$ \\
\hline & 1998 & 822.6 & 113.9 & 474.8 & 219.1 & $1,736.6$ & 637.7 & 80.3 & 898.6 & 371.1 & $2,121.6$ \\
\hline & 2007 & $1,121.6$ & 95.7 & 548.3 & 212.4 & $2,404.6$ & 903.8 & 194.5 & 804.4 & 416.6 & $3,000.7$ \\
\hline & 2016 & 979.1 & 354.3 & - & 232.3 & $2,191.3$ & 785.7 & 301.5 & 400.6 & 427.0 & $2,796.8$ \\
\hline
\end{tabular}

Note: Each statistics is actually calculated as the median of the wealth concept for households (by age group and year) within $+/-5$ percentage points of the cut point of the combined-wealth distribution. So, the values for P10 of the combined-wealth distribution is the median of the wealth concept for households between the 5 th and 15 th percentiles of the combined-wealth distribution. 
Table 3. Annualized-Wealth-to-Poverty Ratio, Mean and Shares below Poverty, by Age Group

\begin{tabular}{|c|c|c|c|c|c|c|c|c|c|c|}
\hline & 1989 & 1992 & 1995 & 1998 & 2001 & 2004 & 2007 & 2010 & 2013 & 2016 \\
\hline \multicolumn{11}{|l|}{ Panel A. All Households (40-59) } \\
\hline \multicolumn{11}{|l|}{ Mean Income/Poverty Ratio: } \\
\hline Annuitized Total Wealth & 7.4 & 6.8 & 7.1 & 7.6 & 8.8 & 8.7 & 9.2 & 7.5 & 7.4 & 8.1 \\
\hline Annuitized Wealth Less Housing & 5.4 & 5.3 & 5.6 & 6.2 & 7.0 & 6.6 & 6.9 & 6.0 & 6.0 & 6.5 \\
\hline \multicolumn{11}{|c|}{$\begin{array}{l}\text { Share of Households below Multiple of Poverty } \\
\text { Threshold }\end{array}$} \\
\hline $1 \mathrm{X}$ Poverty & $11.3 \%$ & $9.8 \%$ & $9.6 \%$ & $8.9 \%$ & $9.7 \%$ & $10.6 \%$ & $10.7 \%$ & $14.3 \%$ & $14.8 \%$ & $15.0 \%$ \\
\hline 1.5 X Poverty & $16.9 \%$ & $15.0 \%$ & $14.1 \%$ & $14.9 \%$ & $14.8 \%$ & $16.6 \%$ & $17.5 \%$ & $21.7 \%$ & $23.7 \%$ & $23.3 \%$ \\
\hline $2 \times$ Poverty & $21.7 \%$ & $20.5 \%$ & $19.4 \%$ & $20.0 \%$ & $20.2 \%$ & $21.2 \%$ & $22.4 \%$ & $29.0 \%$ & $32.4 \%$ & $31.6 \%$ \\
\hline \multicolumn{11}{|l|}{ Panel B. Age 40-49 } \\
\hline \multicolumn{11}{|l|}{ Mean Income/Poverty Ratio: } \\
\hline Annuitized Total Wealth & 8.5 & 7.1 & 7.4 & 8.0 & 8.9 & 8.9 & 9.5 & 7.5 & 7.7 & 7.8 \\
\hline Annuitized Wealth Less Housing & 5.9 & 5.4 & 5.6 & 6.3 & 6.8 & 6.5 & 6.6 & 5.8 & 6.1 & 6.0 \\
\hline \multicolumn{11}{|c|}{$\begin{array}{l}\text { Share of Households below Multiple of Poverty } \\
\text { Threshold }\end{array}$} \\
\hline $1 \mathrm{X}$ Poverty & $11.2 \%$ & $9.5 \%$ & $9.6 \%$ & $9.3 \%$ & $10.3 \%$ & $11.2 \%$ & $13.3 \%$ & $16.0 \%$ & $15.5 \%$ & $15.6 \%$ \\
\hline $1.5 \times$ Poverty & $16.7 \%$ & $15.4 \%$ & $13.2 \%$ & $14.2 \%$ & $15.2 \%$ & $16.4 \%$ & $19.0 \%$ & $23.7 \%$ & $23.1 \%$ & $23.4 \%$ \\
\hline $2 \times$ Poverty & $19.7 \%$ & $19.8 \%$ & $17.5 \%$ & $18.2 \%$ & $18.9 \%$ & $20.4 \%$ & $23.1 \%$ & $30.1 \%$ & $31.8 \%$ & $30.5 \%$ \\
\hline \multicolumn{11}{|l|}{ Panel C. Age 50-59 } \\
\hline \multicolumn{11}{|l|}{ Mean Income/Poverty Ratio: } \\
\hline Annuitized Total Wealth & 6.0 & 6.3 & 6.7 & 7.0 & 8.6 & 8.5 & 8.9 & 7.5 & 7.1 & 8.3 \\
\hline Annuitized Wealth Less Housing & 4.7 & 5.3 & 5.7 & 6.0 & 7.3 & 6.9 & 7.1 & 6.2 & 6.0 & 7.1 \\
\hline \multicolumn{11}{|c|}{$\begin{array}{l}\text { Share of Households below Multiple of Poverty } \\
\text { Threshold }\end{array}$} \\
\hline $1 \mathrm{X}$ Poverty & $11.5 \%$ & $10.2 \%$ & $9.5 \%$ & $8.4 \%$ & $8.9 \%$ & $10.0 \%$ & $7.9 \%$ & $12.7 \%$ & $14.1 \%$ & $14.6 \%$ \\
\hline 1.5 X Poverty & $17.2 \%$ & $14.5 \%$ & $15.6 \%$ & $15.9 \%$ & $14.4 \%$ & $16.9 \%$ & $15.8 \%$ & $19.9 \%$ & $24.2 \%$ & $23.2 \%$ \\
\hline $2 \mathrm{X}$ Poverty & $24.2 \%$ & $21.5 \%$ & $22.5 \%$ & $22.3 \%$ & $22.1 \%$ & $22.1 \%$ & $21.7 \%$ & $27.8 \%$ & $33.0 \%$ & $32.6 \%$ \\
\hline
\end{tabular}


References

Ackerman, Samuel, and John E. Sabelhaus. 2012. "The Effect of Self-Reported Transitory Income Shocks on Household Spending." Finance and Economics Discussion Series 2012-64.

Banks, James, Richard Blundell, and James P. Smith. 2003. "Financial Wealth Inequality in the United States and Great Britain." The Journal of Human Resources 38 (2): 241-279.

Bernheim, B. Douglas. 1992. "Is the Baby Boom Generation Preparing Adequately for Retirement? Technical Report.” Unpublished, Merrill Lynch.

Beshears, John, James Choi, David Laibson, and Shanthi Ramnath. 2019. "Trends in Retirement Income Adequacy: Evidence from IRS Tax Data." MRDRC Working Paper.

Biggs, Andrew G., and Glenn R. Springstead. 2008. "Alternate Measures of Replacement Rates for Social Security Benefits and Retirement Income." Social Security Bulletin 68(2): 1-19.

Brady, Peter J., Steven Bass, Jessica Holland, and Kevin Pierce. 2017. "Using Panel Tax Data to Examine the Transition to Retirement." https://ssrn.com/abstract=2928375.

Bricker, Jesse, Alice Henriques, and Kevin B. Moore. 2017. "Updates to the Sampling of Wealthy Families in the Survey of Consumer Finances." Finance and Economics Discussion Series 2017-114.

Bricker, Jesse, Lisa J. Dettling, Alice Henriques, Joanne W. Hsu, Lindsay Jacobs, Kevin B. Moore, Sarah Pack, John Sabelhaus, Jeffrey Thompson, and Richard A. Windle. 2017. "Changes in U.S. Family Finances from 2013 to 2016: Evidence from the Survey of Consumer Finances." Federal Reserve Bulletin 103(3).

Bricker, Jesse, Kevin B. Moore, and Jeffrey P. Thompson. 2019. "Trends in Household Portfolio Composition." In Handbook of US Consumer Economics, ed. Andrew Haughwout and Benjamin Mandel, 53-96. Cambridge, MA: Academic Press.

Bricker, Jesse, and Gary V. Engelhardt. 2014. "A Test for Selection in Matched Administrative Earnings Data." Journal of Economic and Social Measurement 39(4): 247-255.

Bricker, Jesse, Alice Henriques, Jacob Krimmel, and John Sabelhaus. 2016. "Measuring Income and Wealth at the Top Using Administrative and Survey Data." Brookings Papers on Economic Activity Spring: 261-321.

Devlin-Foltz, Sebastian, Alice Henriques, and John Sabelhaus. 2016. "Is the U.S. Retirement System Contributing to Rising Wealth Inequality?" The Russell Sage Foundation Journal of the Social Sciences 2(6): 59-85.

Engen, Eric M., William G. Gale, and Cori E. Uccello. 1999. "The Adequacy of Household Saving." Brookings Papers on Economic Activity 2: 65-187.

Fisher, Jonathan, David Johnson, Jonathan Latner, Timothy Smeeding, and Jeffrey Thompson. 2016. "Inequality and Mobility Using Income, Consumption, and Wealth for the Same Individuals." The Russell Sage Foundation Journal of the Social Sciences 2(6): 44-58.

Gould, Elise, and David Cooper. 2013. "Financial Security of Elderly Americans at Risk: Proposed Changes to Social Security and Medicare Could Make a Majority of Seniors 'Economically Vulnerable.'” Economic Policy Institute Briefing Paper No. 362. 
Gustman, Alan L., and Thomas L. Steinmeier. 1999. "Effects of Pensions on Savings: Analysis with Data from the Health and Retirement Study." Carnegie-Rochester Series on Public Policy 50: 271-324.

Haveman, Robert, Karen Holden, Barbara Wolfe, and Andrei Romanov. 2006. "The Sufficiency of Retirement Savings: A Comparison of Two Cohorts of Retired Workers at the Time of Retirement." La Follette School Working Paper 2006-019. http://digital.library.wisc.edu/1793/36278.

Hurd, Michael D., and Susann Rohwedder. 2011. "Economic Preparation for Retirement." In Investigations in the Economics of Aging, ed. David A. Wise, 77-113, Chicago, IL: University of Chicago Press.

Internal Revenue Service. 1992. Individual Income Tax Returns, 1990 Internal Revenue Service, United States.

Juster, Thomas F., James P. Smith, and Frank P. Stafford. 1999. "The Measurement and Structure of Household Wealth." Labour Economics 6(2): 253-275.

Keister, Lisa A, and Stephanie Moller. 2000. "Wealth Inequality in the United States." Annual Review of Sociology 26: 63-81.

Kennickell, Arthur B. 1999. "Revisions to the SCF Weighting Methodology: Accounting for Race/Ethnicity and Homeownership." FRB Working Paper. Washington: Board of Governors of the Federal Reserve System.

Kennickell, Arthur B. 2006. "Currents and Undercurrents: Changes in the Distribution of Wealth, 19892004." Finance and Economics Discussion Series. Washington: Board of Governors of the Federal Reserve System. https://www.federalreserve.gov/pubs/feds/2006/200613/200613pap.pdf.

Kennickell, Arthur B., and Annika E. Sundén. 1997. "Pensions, Social Security, and the Distribution of Wealth. Finance and Economics Discussion Series. Washington: Board of Governors of the Federal Reserve System. https://www.federalreserve.gov/pubs/feds/1997/199755/199755pap.pdf.

Love, David A., Paul A. Smith, and Lucy C. McNair. 2008. "A New Look at the Wealth Adequacy of Older U.S. Households." Review of Income and Wealth 54(4): 616-642.

Munnell, Alicia H., Natalia Orlova, and Anthony Webb. 2013. "How Important Is Asset Allocation to Americans' Financial Retirement Security?" In The Market for Retirement Financial Advice, ed. Olivia S. Mitchell and Kent Smetters, 89-106. New York, NY: Oxford University Press.

Munnell, Alicia H., Matthew S. Rutledge, and Anthony Webb. 2014. "Are Retirees Falling Short? Reconciling the Conflicting Evidence." Center for Retirement Research at Boston College Working Paper 2014-16. http://crr.bc.edu/working-papers/are-retirees-falling-short-reconcilingthe-conflicting-evidence/.

Munnell, Alicia H., Anthony Webb, and Luke Delorme. 2006. "A New National Retirement Risk Index." Issue in Brief 48. Center for Retirement Research at Boston College. http://crr.bc.edu/briefs/anew-national-retirement-risk-index/.

Munnell, Alicia, Wenliang Hou, and Geoffrey Sanzenbacher. 2018). "National Retirement Risk Index Shows Modest Improvement in 2016." Center for Retirement Research at Boston College Working Paper 2018-1. http://crr.bc.edu/briefs/national-retirement-risk-index-shows-modestimprovement-in-2016/. 
Mutchler, Jan, Yang Li, and Ping Xu. 2016. "Living Below the Line: Economic Insecurity and Older Americans Insecurity in the States 2016." Center for Social and Demographic Research on Aging Publications (University of Massachusetts Boston) Paper No. 13.

Pfeffer, Fabian T., Robert F. Schoeni, Arthur Kennickell, and Patricia Andreski. 2016. "Measuring Wealth and Wealth Inequality: Comparing Two U.S. Surveys." Journal of Economic and Social Measurement 41(2): 103-120.

Quadrini, Vincenzo. 1999. "The Importance of Entrepreneurship for Wealth Concentration and Mobility." The Review of Income and Wealth 45(1): 1-19.

Saez, Emmanuel, and Gabriel Zucman. 2016. "Wealth Inequality in the United States since 1913: Evidence from Capitalized Income Tax Data." Quarterly Journal of Economics 131(2): 519578.

Scholz, John Karl, Ananth Seshardi, and Surachai Khitatrakun. 2006. 'Are Americans Saving 'Optimally' for Retirement?" Journal of Political Economy 114(4): 607-643.

Social Security Administration, 2016. Income of the Aged Chartbook, 2014

Starr-McCluer, Martha, and Annika Sunden. 1999). "Workers' Knowledge of Their Pension Coverage: A Reevaluation." In The Creation and Analysis of Employer-Employee Matched Data (Contributions to Economic Analysis, Volume 241), ed. John C. Haltiwanger, Julia I. Lane, James.R. Spletzer, Jules J.M. Theeuwes, and Kenneth R. Troske, 469-583. Bingley, UK: Emerald Group Publishing.

Wilson, Oliver H., and William J. Smith Jr. 1983, "Access to Tax Records for Statistical Purposes." Proceedings of the Section on Survey Research Methods Section, American Statistical Association, 595-601.

Wolff, Edward N. 1995. Top Heavy: A Study of the Increasing Inequality of Wealth in America. New York, NY: Twentieth Century Fund Press.

Wolff, Edward N. 2002. "Inheritances and Wealth Inequality, 1989-1998. American Economic Review 92(2): 260-264.

Wolff, Edward N. 2007. "The Retirement Wealth of the Baby Boom Generation." Journal of Monetary Economics 54(1): 1-40.

Wolff, Edward N. 2014. "Household Wealth Trends in the United States, 1983-2010." Oxford Review of Economic Policy 30(1): 21-43.

Wolff, Edward N. 2015. "U.S. Pensions in the 2000s: The Lost Decade?" Review of Income and Wealth 61(4): 599-629. 


\section{Appendix A. Distributing Aggregate DB Pension Assets}

The Survey of Consumer Finances (SCF) does not ask respondents about the present value of expected future defined benefit (DB) pensions, but the survey does collect information about current DB payments of retirees and about the expected future claims of workers from DB pension plans.

First, the aggregate value of DB assets by year is assigned as the value from the Federal Reserve Board's Financial Accounts (FA) of the United States. ${ }^{22}$ DB pension wealth is the portion of Total Pension Entitlements (B.101 line 28) not found in defined contribution pension assets (Table L.116 line 26). In the first quarter of 2016, this amounted to $\$ 15.1$ trillion, or roughly onesixth of the FA household sector's total net worth. This is defined as the accrued benefit obligation of pension plans to households, and as such, it includes both funded and unfunded assets.

Aggregate DB wealth is distributed across households in a series of steps. We build off the approach used by Bricker et al. (2016), which was inspired by the approach used by Saez and Zucman (2016).

The first phase of the micro allocation involves splitting aggregate pension wealth between (1) SCF respondents already receiving benefits or those with coverage from a past job and (2) those who are currently covered by DB plans on their job but not yet receiving benefits. We effectively assume that current beneficiaries (or those who have coverage from a past job) have a first claim to plan assets, as we solve for the present value of promised benefits for group (1) and subtract that amount from total plan assets to solve for the share to be distributed to those not yet receiving benefits (with coverage from their current job). The present value of benefits for those already receiving them is based on the respondent-reported values for those benefits, cohort life tables from the Social Security Administration, differential mortality estimates from the Congressional Budget Office, and an assumed nominal discount factor that varies over time. The present value of benefits is calculated similarly for those who report coverage from a past job,

\footnotetext{
${ }^{22}$ Financial Accounts data are available on the Federal Reserve Board's website, in the quarterly Z1 release. The data can be accessed at http://www.federalreserve.gov/releases/z1/.
} 
relying on expected payment and age at which benefits will begin. The total present value of all these benefits is then subtracted from the FA aggregate, creating a "residual."

The algorithm we use for assigning DB assets to respondents (and spouses if present) in group (2), those with coverage on their current job, is not based on SCF respondent-reported expected DB benefits. For this group, we follow in spirit how the plan would be required to fund their pension plan, through accrued benefit obligation (ABO). Thus, we rely on current wage and years in the plan, and an assumed accrual of 2 percent of wages gained per year toward the annual benefit to estimate $\mathrm{ABO}$ for each individual. Then, to ensure the household sector aggregate matches the total assets from the FA, the ABO for each worker is scaled so that the total benefits from this second step match the "residual" calculated after the first estimation step. 
Appendix Figure 1A. Median Wage for Men Born 1933-1935, SCF Predictions and CPS Values

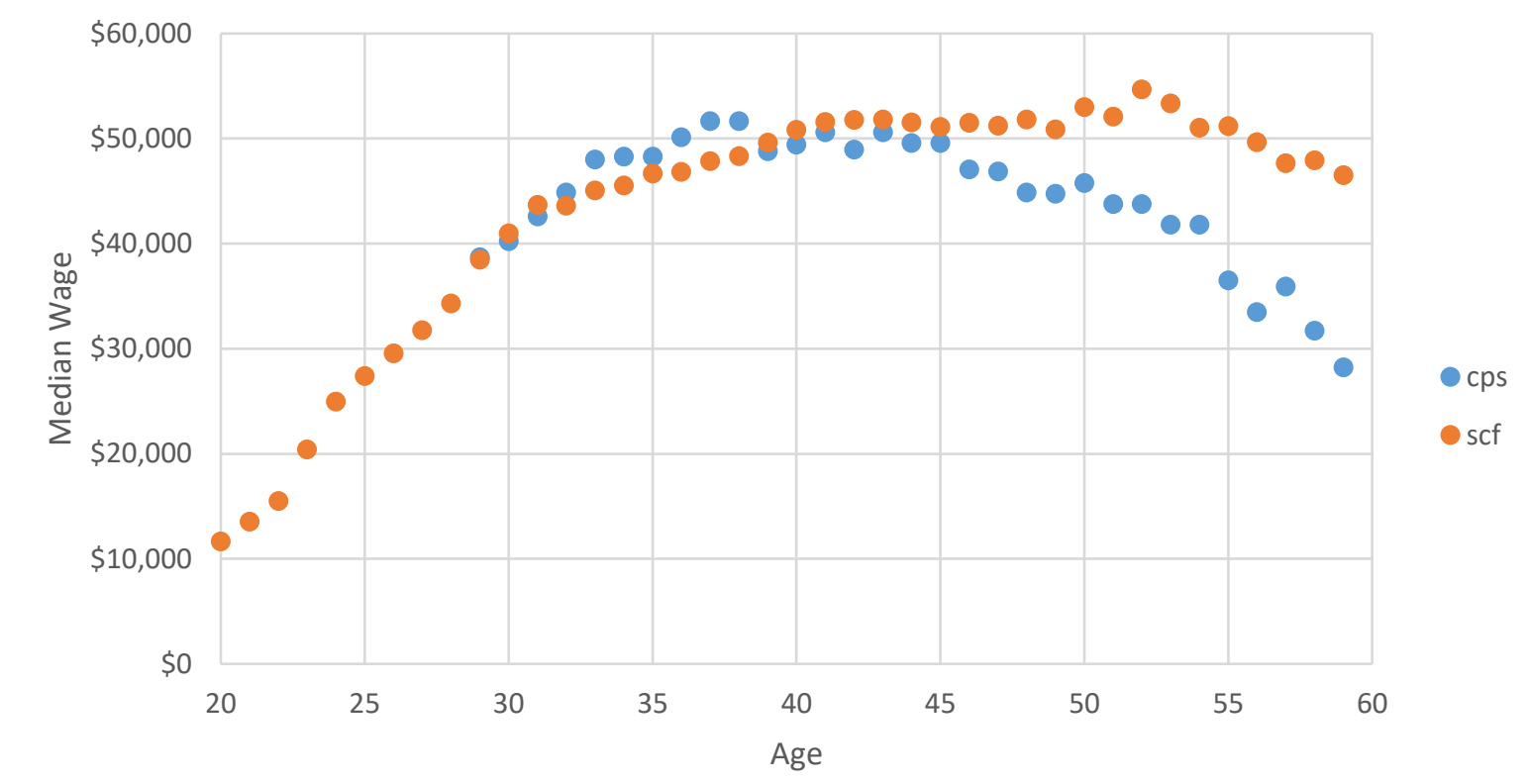

Note: The SCF estimates are from applying estimates from CPS earnings regressions to SCF respondents. The CPS values are raw medians from microdata.

Appendix Figure 1B. Median Wage for Men Born 1957-1959, SCF Predictions and CPS Values

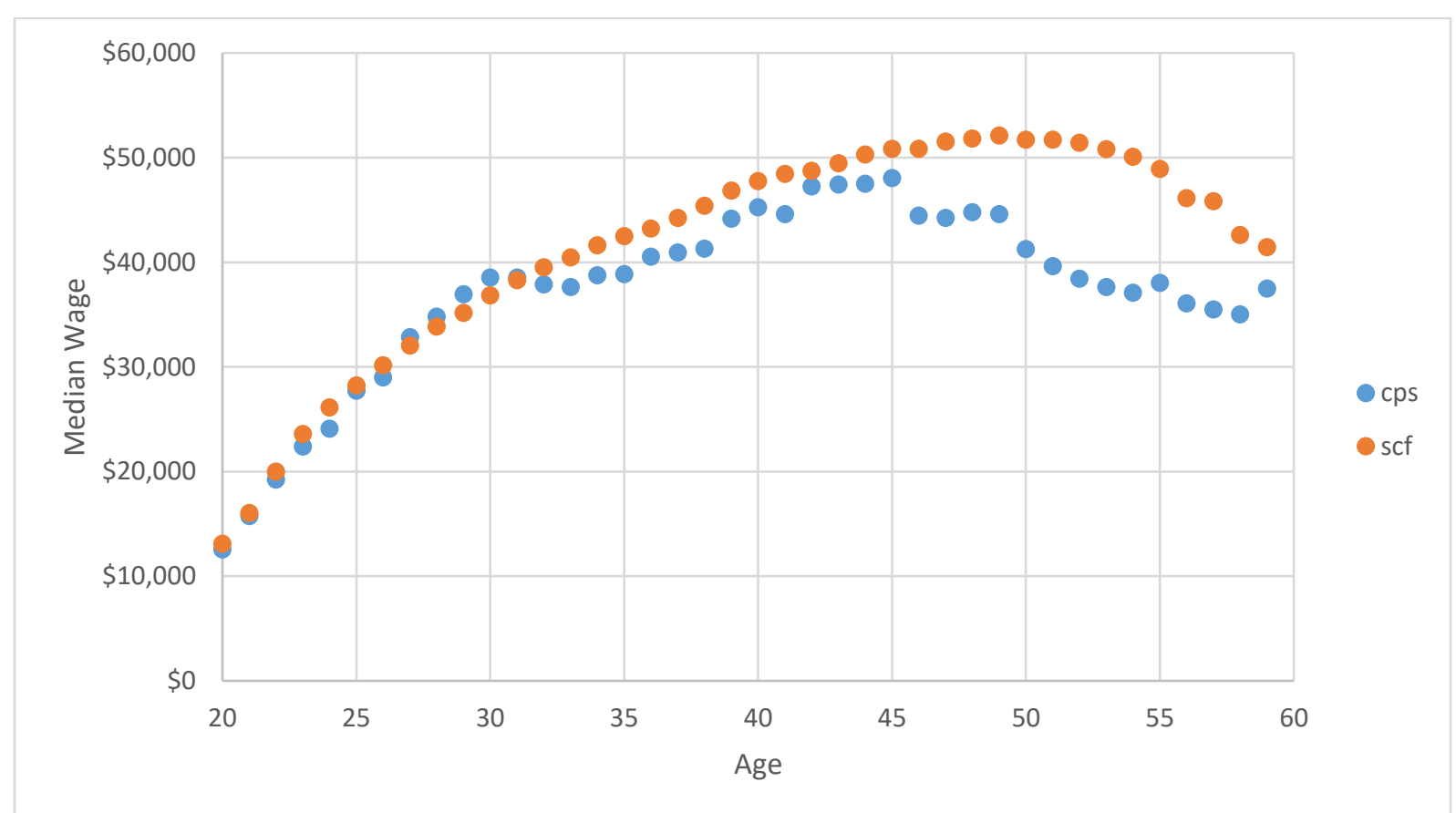

Note: The SCF estimates are from applying estimates from CPS earnings regressions to SCF respondents. The CPS values are raw medians from microdata. 
Appendix Figure 2. Implied Annual Growth Rates from Net Worth Projections: Growth Rates at Each Age from 40 to 63 for Nine Income/Wealth Cohorts

A. Low-wealth cohorts

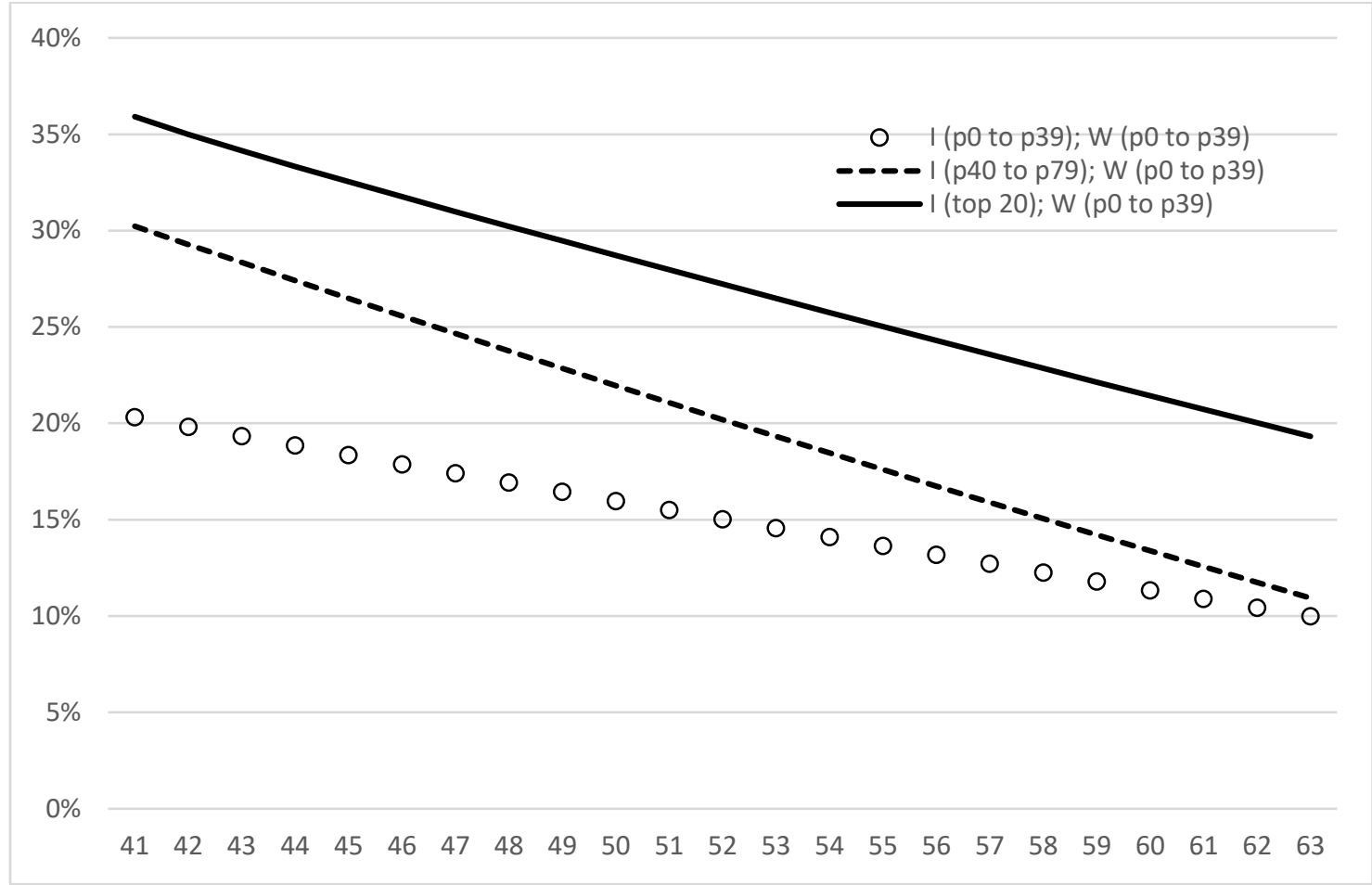

B. Middle- and high-wealth cohorts

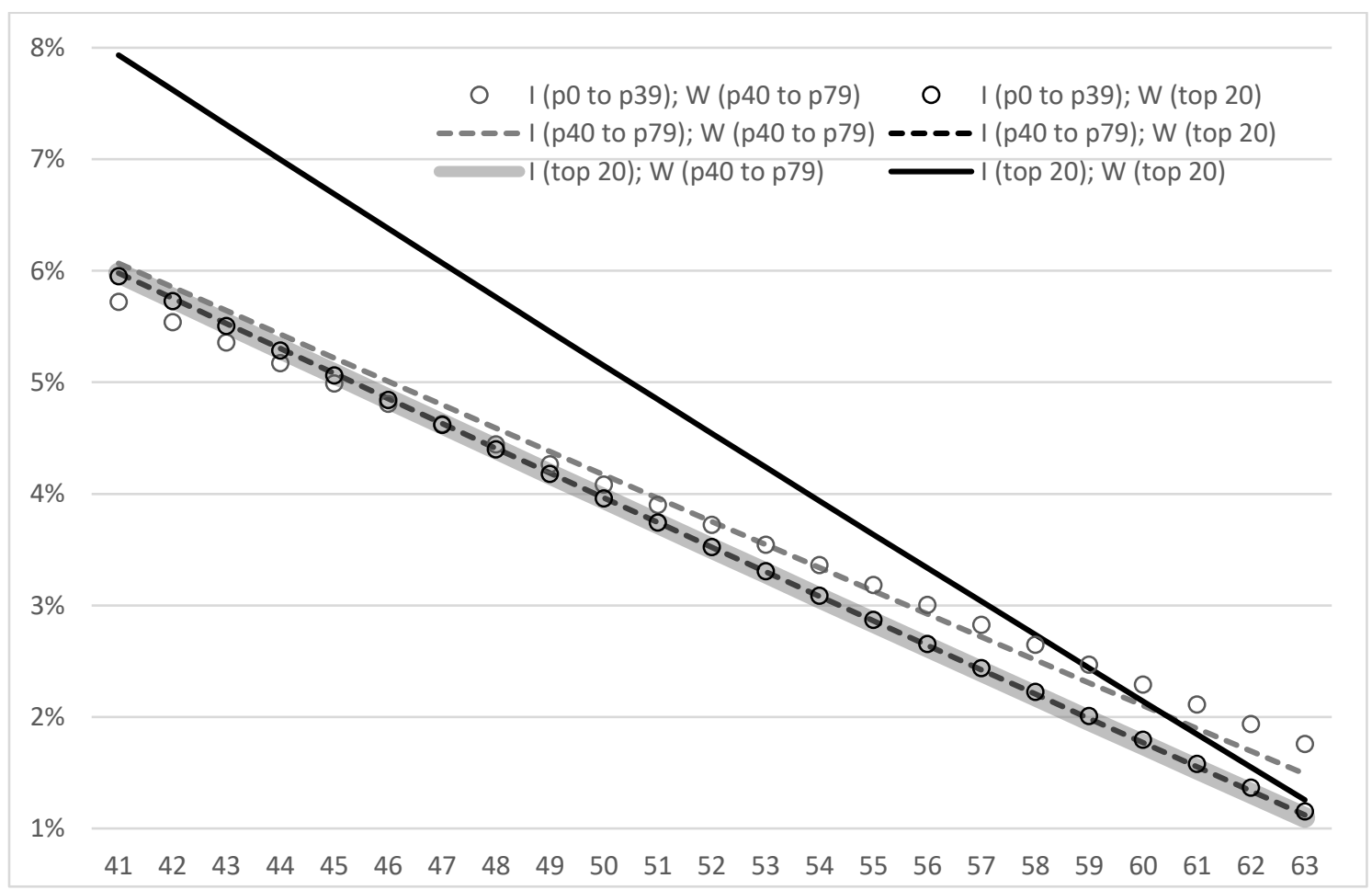


Appendix Figure 3. Mean Combined Wealth by Age of Household Head in 2016-Comparing Current Combined Wealth with Projected Discounted Combined Wealth (3-year smoothed average) (thousands \$)

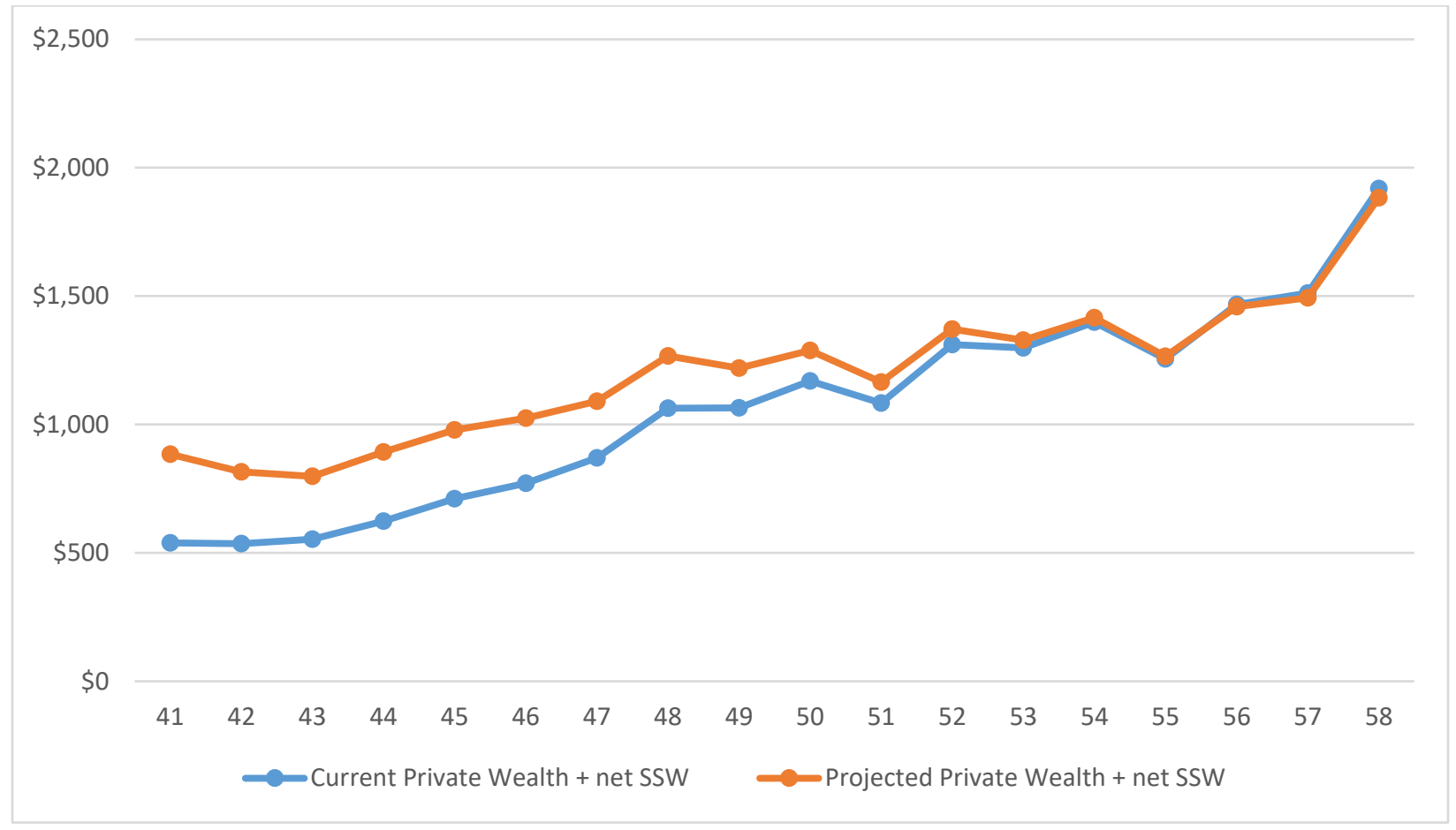

Note: Average wealth has 2016 SCF survey year level, including expected net Social Security wealth. 
Appendix Table 1. Mean Retirement Wealth by Type, Year, and Age Group, Real 2016 \$ (thousands)

\begin{tabular}{|c|c|c|c|c|c|c|c|c|c|c|c|c|}
\hline & & 1989 & 1992 & 1995 & 1998 & 2001 & 2004 & 2007 & 2010 & 2013 & 2016 & $\begin{array}{r}\% \text { Change } \\
1989 \text { to } 2016\end{array}$ \\
\hline \multirow[t]{7}{*}{ Age 40-49 } & Projected Non-retirement wealth & 670.8 & 523.8 & 538.5 & 612.5 & 705.7 & 752.7 & 773.5 & 602.0 & 605.3 & 595.6 & $-11 \%$ \\
\hline & Projected DC Wealth & 55.9 & 45.4 & 69.3 & 82.9 & 103.5 & 86.3 & 94.7 & 94.2 & 98.7 & 116.1 & $108 \%$ \\
\hline & DB Wealth & 89.7 & 128.0 & 131.5 & 124.6 & 132.4 & 130.3 & 155.5 & 121.3 & 125.6 & 147.7 & $65 \%$ \\
\hline & DC (Projected) + DB Wealth & 145.5 & 173.8 & 200.7 & 207.5 & 235.9 & 216.6 & 250.1 & 215.6 & 224.3 & 263.8 & $81 \%$ \\
\hline & Non-retirement (Proj) + DC (Proj) + DB wealth & 816.3 & 697.6 & 739.3 & 820.0 & 941.6 & 969.3 & 1023.7 & 817.6 & 829.6 & 859.4 & $5 \%$ \\
\hline & Net SS wealth & 127.3 & 140.0 & 147.9 & 141.5 & 143.5 & 150.3 & 142.2 & 144.0 & 141.2 & 149.5 & $17 \%$ \\
\hline & Proj Combined Wealth & 943.6 & 837.8 & 887.2 & 961.5 & 1085.1 & 1119.7 & 1165.9 & 961.6 & 970.8 & 1008.9 & $7 \%$ \\
\hline \multirow[t]{7}{*}{ Age 50-59 } & Projected Non-retirement wealth & 501.3 & 500.1 & 554.8 & 628.2 & 801.8 & 810.7 & 857.0 & 669.5 & 603.7 & 853.7 & $70 \%$ \\
\hline & Projected DC Wealth & 46.2 & 71.8 & 82.8 & 91.5 & 129.9 & 132.0 & 148.2 & 142.8 & 135.7 & 158.7 & $244 \%$ \\
\hline & DB Wealth & 162.9 & 201.7 & 218.2 & 210.0 & 277.7 & 243.9 & 238.5 & 239.8 & 209.7 & 206.1 & $27 \%$ \\
\hline & DC (Projected) + DB Wealth & 209.1 & 274.0 & 301.0 & 301.5 & 407.5 & 375.9 & 386.7 & 382.6 & 345.4 & 364.8 & $74 \%$ \\
\hline & Non-retirement (Proj) + DC (Proj) + DB wealth & 710.4 & 774.2 & 855.9 & 929.7 & 1209.3 & 1186.6 & 1243.7 & 1052.2 & 949.1 & 1218.5 & $72 \%$ \\
\hline & Net SS wealth & 189.4 & 217.6 & 217.7 & 229.3 & 241.3 & 240.0 & 251.8 & 249.2 & 241.4 & 238.1 & $26 \%$ \\
\hline & Proj Combined Wealth & 899.8 & 992.3 & 1073.6 & 1158.9 & 1450.6 & 1426.7 & 1495.5 & 1301.3 & 1190.5 & 1456.6 & $62 \%$ \\
\hline \multirow[t]{7}{*}{ Age 40-59 } & Projected Non-retirement wealth & 596.5 & 514.2 & 544.7 & 619.3 & 745.4 & 779.5 & 812.8 & 636.4 & 604.5 & 732.0 & $23 \%$ \\
\hline & Projected DC Wealth & 51.7 & 56.1 & 74.4 & 86.6 & 114.4 & 107.3 & 119.9 & 119.0 & 118.0 & 138.6 & $168 \%$ \\
\hline & DB Wealth & 121.8 & 158.0 & 164.4 & 161.4 & 192.4 & 182.7 & 194.5 & 181.7 & 169.3 & 178.5 & $47 \%$ \\
\hline & DC (Projected) + DB Wealth & 173.4 & 214.4 & 238.8 & 248.0 & 306.8 & 290.1 & 314.4 & 300.7 & 287.3 & 317.2 & $83 \%$ \\
\hline & Non-retirement (Proj) + DC (Proj) + DB wealth & 769.9 & 728.6 & 783.5 & 867.3 & 1052.2 & 1069.5 & 1127.2 & 937.1 & 891.7 & 1049.2 & $36 \%$ \\
\hline & Net SS wealth & 154.5 & 171.5 & 174.4 & 179.4 & 183.9 & 191.7 & 193.8 & 197.6 & 193.3 & 196.3 & $27 \%$ \\
\hline & Proj Combined Wealth & 924.4 & 900.4 & 957.9 & 1046.7 & 1236.1 & 1261.2 & 1321.0 & 1134.7 & 1085.0 & 1245.5 & $35 \%$ \\
\hline
\end{tabular}

Note: All components of combined wealth are projected to either age 62 or, for DB wealth, the age individuals expect to stop working at their current job. 
Appendix Table 2. Median Retirement Wealth by Type, Year, and Age Group, Real 2016 \$ (thousands)

\begin{tabular}{|c|c|c|c|c|c|c|c|c|c|c|c|c|}
\hline & & 1989 & 1992 & 1995 & 1998 & 2001 & 2004 & 2007 & 2010 & 2013 & 2016 & $\begin{array}{r}\% \text { Change } \\
1989 \text { to } 2016\end{array}$ \\
\hline \multirow[t]{7}{*}{ Age $40-49$} & Projected Non-retirement wealth & 395.7 & 267.1 & 290.5 & 315.5 & 345.9 & 322.8 & 337.8 & 192.2 & 153 & 194.1 & $-51 \%$ \\
\hline & Projected DC Wealth & 0 & 0.4 & 2 & 3.8 & 5.2 & 3.4 & 5.6 & 2.8 & 2.5 & 4.2 & NA \\
\hline & DB Wealth & 0 & 0 & 0 & 0 & 0 & 0 & 0 & 0 & 0 & 0 & NA \\
\hline & DC (Projected) + DB Wealth & 30.6 & 37.4 & 30.5 & 35 & 32.8 & 29 & 21.2 & 12.6 & 13 & 20.3 & $-34 \%$ \\
\hline & Non-retirement (Proj) + DC (Proj) + DB & 509.9 & 410.6 & 428.2 & 443.5 & 471.4 & 472.7 & 453.9 & 277.5 & 255.9 & 303.8 & $-40 \%$ \\
\hline & Net SS wealth & 118 & 133.3 & 144.5 & 130 & 131.7 & 141.3 & 130.9 & 136.6 & 129.4 & 141.8 & $20 \%$ \\
\hline & Proj Combined Wealth & 638.6 & 555.9 & 584.9 & 595 & 642.6 & 633.2 & 623.7 & 435.2 & 411.6 & 463.2 & $-27 \%$ \\
\hline \multirow[t]{7}{*}{ Age 50-59 } & Projected Non-retirement wealth & 219.6 & 203 & 205.8 & 201 & 236.4 & 262.8 & 255.2 & 166.6 & 131.6 & 141.8 & $-35 \%$ \\
\hline & Projected DC Wealth & 0.6 & 2 & 3.4 & 4.2 & 9.7 & 7.4 & 16.3 & 6.5 & 6 & 6.4 & $967 \%$ \\
\hline & DB Wealth & 2 & 19.6 & 0 & 0 & 0 & 0 & 0 & 0 & 0 & 0 & $-100 \%$ \\
\hline & DC (Projected) + DB Wealth & 52.2 & 107.9 & 81.8 & 65 & 93.9 & 68.7 & 78.7 & 50.6 & 45.7 & 37.4 & $-28 \%$ \\
\hline & Non-retirement (Proj) + DC (Proj) + DB & 348.8 & 387.6 & 380.3 & 369.4 & 479.8 & 487.5 & 431.4 & 323.3 & 273.2 & 239 & $-31 \%$ \\
\hline & Net SS wealth & 178.9 & 209.7 & 205.3 & 221.1 & 231.8 & 214.3 & 233.2 & 221.8 & 218.8 & 206.6 & $15 \%$ \\
\hline & Proj Combined Wealth & 571 & 621.9 & 612.1 & 629.5 & 742.8 & 712.9 & 746.9 & 589.4 & 514.7 & 492.6 & $-14 \%$ \\
\hline \multirow[t]{7}{*}{ Age 40-59 } & Projected Non-retirement wealth & 305.5 & 242.6 & 257.2 & 271.1 & 299.3 & 294.9 & 293.9 & 176.6 & 140.8 & 164.3 & $-46 \%$ \\
\hline & Projected DC Wealth & 0.2 & 0.9 & 2.4 & 3.9 & 6.6 & 5.6 & 9.6 & 4.6 & 4.3 & 5.1 & $2450 \%$ \\
\hline & DB Wealth & 0.4 & 0 & 0 & 0 & 0 & 0 & 0 & 0 & 0 & 0 & $-100 \%$ \\
\hline & DC (Projected) + DB Wealth & 38.3 & 58.2 & 46.5 & 43.9 & 52.2 & 45.9 & 42.3 & 25.6 & 26.6 & 29 & $-24 \%$ \\
\hline & Non-retirement (Proj) + DC (Proj) + DB & 445.5 & 402.9 & 414.4 & 420.5 & 477.5 & 477.9 & 446.1 & 297.8 & 261.5 & 267.7 & $-40 \%$ \\
\hline & Net SS wealth & 147 & 163.5 & 165.2 & 161.1 & 166.2 & 167.9 & 172 & 171.8 & 169.9 & 173.1 & $18 \%$ \\
\hline & Proj Combined Wealth & 603.5 & 581.4 & 592.5 & 612 & 684.1 & 671 & 667.3 & 500.8 & 460.1 & 482.7 & $-20 \%$ \\
\hline
\end{tabular}


Appendix Table 3. Distribution of Wealth-to-Income Ratio by Wealth Concept, Year, and Age Group

\begin{tabular}{|c|c|c|c|c|c|c|c|c|c|c|}
\hline \multirow[t]{2}{*}{$6 \mathrm{~A}}$. & \multicolumn{10}{|c|}{ Age Group 40-49 } \\
\hline & 1989 & 1992 & 1995 & 1998 & 2001 & 2004 & 2007 & 2010 & 2013 & 2016 \\
\hline \multicolumn{11}{|c|}{ Panel A. DB + Projected DC Wealth to Income Ratio } \\
\hline P25 & - & - & - & - & - & - & - & - & - & - \\
\hline P50 & 0.4 & 0.5 & 0.4 & 0.4 & 0.4 & 0.4 & 0.3 & 0.2 & 0.2 & 0.2 \\
\hline Mean & 1.4 & 2.1 & 2.2 & 2.5 & 2.2 & 2.0 & 2.3 & 2.0 & 2.2 & 2.2 \\
\hline P75 & 2.0 & 2.9 & 3.2 & 2.9 & 2.9 & 2.1 & 2.1 & 1.7 & 1.9 & 1.8 \\
\hline P90 & 3.6 & 6.2 & 7.1 & 8.3 & 7.3 & 6.6 & 8.0 & 7.0 & 6.8 & 7.4 \\
\hline Mean/Median & 3.5 & 4.2 & 5.5 & 6.3 & 5.5 & 5.0 & 7.7 & 10.0 & 11.0 & 11.0 \\
\hline P90/P50 & 9.0 & 12.4 & 17.8 & 20.8 & 18.3 & 16.5 & 26.7 & 35.0 & 34.0 & 37.0 \\
\hline \multicolumn{11}{|c|}{ Panel B. DB + Projected DC + SS Wealth to Income Ratio } \\
\hline P25 & 1.5 & 1.9 & 2.1 & 1.7 & 1.7 & 1.7 & 1.7 & 1.7 & 1.7 & 1.6 \\
\hline P50 & 2.6 & 3.4 & 3.4 & 2.9 & 2.9 & 2.8 & 2.8 & 2.7 & 2.8 & 2.7 \\
\hline Mean & 3.5 & 4.9 & 4.8 & 4.6 & 4.3 & 4.2 & 4.4 & 4.4 & 4.5 & 4.4 \\
\hline P75 & 4.2 & 5.8 & 6.1 & 5.6 & 5.5 & 5.0 & 4.9 & 5.1 & 5.0 & 4.8 \\
\hline P90 & 6.9 & 9.1 & 9.7 & 10.4 & 9.4 & 9.2 & 10.3 & 10.1 & 10.2 & 10.3 \\
\hline Mean/Median & 1.3 & 1.4 & 1.4 & 1.6 & 1.5 & 1.5 & 1.6 & 1.6 & 1.6 & 1.6 \\
\hline P90/P50 & 2.7 & 2.7 & 2.9 & 3.6 & 3.2 & 3.3 & 3.7 & 3.7 & 3.6 & 3.8 \\
\hline \multicolumn{11}{|c|}{ Panel C. Projected Combined Wealth to Income Ratio } \\
\hline P25 & 5.6 & 5.0 & 5.4 & 4.8 & 4.8 & 4.9 & 4.5 & 3.7 & 3.5 & 3.6 \\
\hline P50 & 8.5 & 8.0 & 8.7 & 8.2 & 8.4 & 8.1 & 8.2 & 6.5 & 5.9 & 6.1 \\
\hline Mean & 10.2 & 11.1 & 10.9 & 10.9 & 11.0 & 10.5 & 10.5 & 9.2 & 9.3 & 8.7 \\
\hline P75 & 12.6 & 12.0 & 12.9 & 13.1 & 13.5 & 13.0 & 14.0 & 11.0 & 10.8 & 10.5 \\
\hline P90 & 18.7 & 18.3 & 19.6 & 20.2 & 20.1 & 18.4 & 21.9 & 18.4 & 18.6 & 18.2 \\
\hline Mean/Median & 1.2 & 1.4 & 1.3 & 1.3 & 1.3 & 1.3 & 1.3 & 1.4 & 1.6 & 1.4 \\
\hline P90/P50 & 2.2 & 2.3 & 2.3 & 2.5 & 2.4 & 2.3 & 2.7 & 2.8 & 3.2 & 3.0 \\
\hline
\end{tabular}


Appendix Table 4. Distribution of Wealth-to-Income Ratio by Wealth Concept, Year, and Age Group

\begin{tabular}{|c|c|c|c|c|c|c|c|c|c|c|}
\hline \multirow[t]{2}{*}{$6 \mathrm{~B}}$. & \multicolumn{10}{|c|}{ Age 50-59 } \\
\hline & 1989 & 1992 & 1995 & 1998 & 2001 & 2004 & 2007 & 2010 & 2013 & 2016 \\
\hline \multicolumn{11}{|c|}{ Panel A. DB + Projected DC Wealth to Income Ratio } \\
\hline P25 & - & - & - & - & - & - & - & - & - & - \\
\hline P50 & 0.7 & 1.6 & 1.3 & 0.9 & 1.1 & 0.8 & 0.8 & 0.7 & 0.6 & 0.5 \\
\hline Mean & 2.4 & 3.3 & 3.6 & 3.3 & 3.8 & 3.3 & 3.4 & 3.3 & 3.4 & 3.0 \\
\hline P75 & 3.5 & 5.0 & 5.8 & 5.1 & 6.1 & 4.2 & 4.0 & 4.5 & 4.2 & 3.2 \\
\hline P90 & 6.9 & 8.4 & 10.4 & 10.8 & 11.9 & 11.7 & 11.2 & 11.6 & 11.8 & 10.4 \\
\hline Mean/Median & 3.4 & 2.1 & 2.8 & 3.7 & 3.5 & 4.1 & 4.3 & 4.7 & 5.7 & 6.0 \\
\hline P90/P50 & 9.9 & 5.3 & 8.0 & 12.0 & 10.8 & 14.6 & 14.0 & 16.6 & 19.7 & 20.8 \\
\hline \multicolumn{11}{|c|}{ Panel B. DB + Projected DC + SS Wealth to Income Ratio } \\
\hline P25 & 2.6 & 3.4 & 3.2 & 3.0 & 3.0 & 2.9 & 3.1 & 3.2 & 3.2 & 3.0 \\
\hline P50 & 4.4 & 5.8 & 5.5 & 5.3 & 5.2 & 4.7 & 5.0 & 5.3 & 5.3 & 4.8 \\
\hline Mean & 5.9 & 8.1 & 7.3 & 7.1 & 7.4 & 7.0 & 7.0 & 7.3 & 7.5 & 7.0 \\
\hline P75 & 7.6 & 9.2 & 10.1 & 9.6 & 9.9 & 8.8 & 8.5 & 9.6 & 9.3 & 9.0 \\
\hline P90 & 12.0 & 14.8 & 14.7 & 15.2 & 16.1 & 15.6 & 16.1 & 16.0 & 17.1 & 16.2 \\
\hline Mean/Median & 1.3 & 1.4 & 1.3 & 1.3 & 1.4 & 1.5 & 1.4 & 1.4 & 1.4 & 1.5 \\
\hline P90/P50 & 2.7 & 2.6 & 2.7 & 2.9 & 3.1 & 3.3 & 3.2 & 3.0 & 3.2 & 3.4 \\
\hline \multicolumn{11}{|c|}{ Panel C. Projected Combined Wealth to Income Ratio } \\
\hline P25 & 5.6 & 6.4 & 6.3 & 6.0 & 5.8 & 6.0 & 5.9 & 5.5 & 5.0 & 5.0 \\
\hline P50 & 8.6 & 9.9 & 9.8 & 9.8 & 9.8 & 9.3 & 9.4 & 8.9 & 8.5 & 8.2 \\
\hline Mean & 11.0 & 13.9 & 12.6 & 12.6 & 13.4 & 13.2 & 12.5 & 11.9 & 11.9 & 11.4 \\
\hline P75 & 13.4 & 15.2 & 15.2 & 15.8 & 16.5 & 15.7 & 15.5 & 15.1 & 14.3 & 14.9 \\
\hline P90 & 20.3 & 23.1 & 22.7 & 22.3 & 26.5 & 26.4 & 24.9 & 23.5 & 23.5 & 23.4 \\
\hline Mean/Median & 1.3 & 1.4 & 1.3 & 1.3 & 1.4 & 1.4 & 1.3 & 1.3 & 1.4 & 1.4 \\
\hline P90/P50 & 2.4 & 2.3 & 2.3 & 2.3 & 2.7 & 2.8 & 2.6 & 2.6 & 2.8 & 2.9 \\
\hline
\end{tabular}


Appendix Table 5. Mean/Median Ratios by Wealth Concept, Age Group, and Year

\begin{tabular}{|c|c|c|c|c|c|c|c|c|}
\hline & \multicolumn{4}{|c|}{ Mean/Median } & \multicolumn{4}{|c|}{$90 / 50$} \\
\hline & 1989 & 1998 & 2007 & 2016 & 1989 & 1998 & 2007 & 2016 \\
\hline \multicolumn{9}{|l|}{ Age $40-49$} \\
\hline Projected Non-retirement wealth & 1.7 & 1.9 & 2.3 & 3.1 & 2.9 & 3.1 & 3.7 & 5.4 \\
\hline Projected non-retirement + Projected DC + DB wealth & 1.6 & 1.8 & 2.3 & 2.8 & 2.7 & 3.5 & 4.8 & 6.5 \\
\hline Projected Combined Wealth & 1.5 & 1.6 & 1.9 & 2.2 & 2.4 & 2.9 & 3.9 & 4.7 \\
\hline \multicolumn{9}{|l|}{ Age $50-59$} \\
\hline Projected Non-retirement wealth & 2.3 & 3.1 & 3.4 & 6.0 & 4.5 & 4.5 & 5.0 & 7.3 \\
\hline Projected non-retirement + Projected DC + DB wealth & 2.0 & 2.5 & 2.9 & 5.1 & 4.3 & 4.8 & 6.1 & 10.0 \\
\hline Projected Combined Wealth & 1.6 & 1.8 & 2.0 & 3.0 & 3.2 & 3.4 & 4.0 & 5.7 \\
\hline \multicolumn{9}{|l|}{ Age 40-59 } \\
\hline Projected Non-retirement wealth & 2.0 & 2.3 & 2.8 & 4.5 & 3.6 & 3.5 & 4.3 & 6.3 \\
\hline Projected non-retirement + Projected DC + DB wealth & 1.7 & 2.1 & 2.5 & 3.9 & 3.2 & 3.9 & 5.4 & 8.3 \\
\hline Projected Combined Wealth & 1.5 & 1.7 & 2.0 & 2.6 & 2.7 & 3.1 & 4.0 & 5.2 \\
\hline
\end{tabular}


Appendix Table 6. Top Shares

\begin{tabular}{|c|c|c|c|c|c|c|c|c|c|}
\hline & \multicolumn{9}{|c|}{ Top 10\% } \\
\hline & \multicolumn{3}{|c|}{ Age: 40 to 49} & \multicolumn{3}{|c|}{ Age 50 to 59} & \multicolumn{3}{|c|}{ Age 40 to 59} \\
\hline & $\begin{array}{l}\text { Projected } \\
\text { Non- } \\
\text { Retirement } \\
\text { Wealth }\end{array}$ & $\begin{array}{l}\text { Projected } \\
\text { non- } \\
\text { retirement + } \\
\text { DC + DB } \\
\text { wealth }\end{array}$ & $\begin{array}{l}\text { Projected } \\
\text { Combined } \\
\text { Wealth } \\
\text { (including } \\
\text { Net SS) }\end{array}$ & $\begin{array}{l}\text { Non- } \\
\text { Retirement } \\
\text { Wealth }\end{array}$ & $\begin{array}{l}\text { Projected } \\
\text { non- } \\
\text { retirement } \\
+\mathrm{DC}+\mathrm{DB} \\
\text { wealth }\end{array}$ & $\begin{array}{l}\text { Projected } \\
\text { Combined } \\
\text { Wealth } \\
\text { (including } \\
\text { Net SS) }\end{array}$ & $\begin{array}{c}\text { Non- } \\
\text { Retirement } \\
\text { Wealth }\end{array}$ & $\begin{array}{l}\text { Projected } \\
\text { non- } \\
\text { retirement } \\
\text { + DC + DB } \\
\text { wealth }\end{array}$ & $\begin{array}{c}\text { Projected } \\
\text { Combined } \\
\text { Wealth } \\
\text { (including } \\
\text { Net SS) }\end{array}$ \\
\hline 1989 & $48.0 \%$ & $45.9 \%$ & $42.0 \%$ & $57.4 \%$ & $48.5 \%$ & $41.1 \%$ & $52.0 \%$ & $47.2 \%$ & $41.9 \%$ \\
\hline 1992 & $53.2 \%$ & $46.6 \%$ & $41.4 \%$ & $59.2 \%$ & $48.4 \%$ & $41.2 \%$ & $55.6 \%$ & $47.7 \%$ & $41.6 \%$ \\
\hline 1995 & $52.2 \%$ & $46.2 \%$ & $40.9 \%$ & $63.7 \%$ & $51.5 \%$ & $44.2 \%$ & $56.7 \%$ & $48.6 \%$ & $42.6 \%$ \\
\hline 1998 & $52.5 \%$ & $47.9 \%$ & $43.0 \%$ & $65.3 \%$ & $55.1 \%$ & $47.3 \%$ & $58.1 \%$ & $51.3 \%$ & $45.2 \%$ \\
\hline 2001 & $52.4 \%$ & $47.3 \%$ & $43.0 \%$ & $67.5 \%$ & $55.8 \%$ & $49.2 \%$ & $59.1 \%$ & $51.6 \%$ & $46.3 \%$ \\
\hline 2004 & $57.3 \%$ & $52.0 \%$ & $47.1 \%$ & $65.3 \%$ & $54.8 \%$ & $48.4 \%$ & $61.1 \%$ & $53.9 \%$ & $48.1 \%$ \\
\hline 2007 & $58.0 \%$ & $52.6 \%$ & $48.1 \%$ & $68.0 \%$ & $58.2 \%$ & $50.6 \%$ & $62.9 \%$ & $55.7 \%$ & $49.9 \%$ \\
\hline 2010 & $66.7 \%$ & $59.9 \%$ & $53.3 \%$ & $68.6 \%$ & $58.2 \%$ & $50.3 \%$ & $67.8 \%$ & $59.3 \%$ & $52.2 \%$ \\
\hline 2013 & $69.3 \%$ & $61.0 \%$ & $54.6 \%$ & $73.3 \%$ & $59.5 \%$ & $50.8 \%$ & $71.4 \%$ & $60.5 \%$ & $52.7 \%$ \\
\hline 2016 & $64.52 \%$ & $57.2 \%$ & $51.2 \%$ & $79.5 \%$ & $67.8 \%$ & $59.5 \%$ & $73.8 \%$ & $63.8 \%$ & $56.6 \%$ \\
\hline
\end{tabular}

\begin{tabular}{|c|c|c|c|c|c|c|c|c|c|}
\hline & \multicolumn{9}{|c|}{ Top 5\% } \\
\hline & \multicolumn{3}{|c|}{ Age: 40 to 49} & \multicolumn{3}{|c|}{ Age: 50 to 59} & \multicolumn{3}{|c|}{ Age: 40 to 59} \\
\hline & $\begin{array}{l}\text { Non- } \\
\text { Retirement } \\
\text { Wealth }\end{array}$ & \begin{tabular}{|l} 
Projected \\
non- \\
retirement \\
$+\mathrm{DC}+\mathrm{DB}$ \\
wealth
\end{tabular} & $\begin{array}{l}\text { Projected } \\
\text { Combined } \\
\text { Wealth } \\
\text { (including } \\
\text { Net SS) }\end{array}$ & $\begin{array}{l}\text { Non- } \\
\text { Retirement } \\
\text { Wealth }\end{array}$ & $\begin{array}{l}\text { Projected } \\
\text { non- } \\
\text { retirement } \\
+\mathrm{DC}+\mathrm{DB} \\
\text { wealth }\end{array}$ & $\begin{array}{l}\text { Projected } \\
\text { Combined } \\
\text { Wealth } \\
\text { (including } \\
\text { Net SS) }\end{array}$ & $\begin{array}{l}\text { Non- } \\
\text { Retirement } \\
\text { Wealth }\end{array}$ & $\begin{array}{l}\text { Projected } \\
\text { non- } \\
\text { retirement } \\
+\mathrm{DC}+\mathrm{DB} \\
\text { wealth }\end{array}$ & $\begin{array}{c}\text { Projected } \\
\text { Combined } \\
\text { Wealth } \\
\text { (including } \\
\text { Net SS) }\end{array}$ \\
\hline 1989 & $39.1 \%$ & $36.3 \%$ & $32.3 \%$ & $45.2 \%$ & $35.7 \%$ & $29.7 \%$ & $41.4 \%$ & $36.2 \%$ & $31.3 \%$ \\
\hline 1992 & $42.9 \%$ & $35.2 \%$ & $30.6 \%$ & $47.6 \%$ & $36.4 \%$ & $29.9 \%$ & $44.8 \%$ & $35.7 \%$ & $30.4 \%$ \\
\hline 1995 & $41.8 \%$ & $34.6 \%$ & $30.1 \%$ & $54.3 \%$ & $40.4 \%$ & $33.7 \%$ & $46.7 \%$ & $37.1 \%$ & $31.8 \%$ \\
\hline 1998 & $42.8 \%$ & $36.6 \%$ & $32.4 \%$ & $55.5 \%$ & $43.2 \%$ & $36.2 \%$ & $48.3 \%$ & $39.8 \%$ & $34.4 \%$ \\
\hline 2001 & $41.9 \%$ & $35.6 \%$ & $31.9 \%$ & $56.5 \%$ & $42.8 \%$ & $36.4 \%$ & $48.6 \%$ & $39.7 \%$ & $35.1 \%$ \\
\hline 2004 & $47.2 \%$ & $40.6 \%$ & $36.2 \%$ & $55.6 \%$ & $42.6 \%$ & $36.8 \%$ & $51.4 \%$ & $41.5 \%$ & $36.6 \%$ \\
\hline 2007 & $47.1 \%$ & $39.5 \%$ & $35.9 \%$ & $57.3 \%$ & $45.3 \%$ & $39.1 \%$ & $52.3 \%$ & $42.9 \%$ & $37.8 \%$ \\
\hline 2010 & $56.5 \%$ & $47.2 \%$ & $41.5 \%$ & $55.5 \%$ & $42.7 \%$ & $36.5 \%$ & $56.4 \%$ & $45.5 \%$ & $39.3 \%$ \\
\hline 2013 & $59.3 \%$ & $48.4 \%$ & $42.5 \%$ & $62.5 \%$ & $46.3 \%$ & $38.5 \%$ & $61.0 \%$ & $47.4 \%$ & $40.5 \%$ \\
\hline 2016 & $53.0 \%$ & $43.3 \%$ & $37.6 \%$ & $69.3 \%$ & $54.4 \%$ & $47.3 \%$ & $63.3 \%$ & $50.9 \%$ & $44.6 \%$ \\
\hline
\end{tabular}


